\title{
Emerging use of nanostructure films containing capped gold nanoparticles in biosensors
}

This article was published in the following Dove Press journal:

Nanotechnology, Science and Applications

6 December 2010

Number of times this article has been viewed

\author{
Jitendra Satija' \\ Reshma Bharadwaj ${ }^{2}$ \\ VVR Sai ${ }^{3}$ \\ Soumyo Mukherji ${ }^{1,2,4}$ \\ 'Department of Bioscience and \\ Bioengineering, IIT Bombay, Mumbai, \\ Maharashtra, India; ${ }^{2}$ Centre of \\ Excellence for Nanoelectronics, IIT \\ Bombay, Mumbai, Maharashtra, India; \\ ${ }^{3}$ Department of Chemistry, University \\ of Idaho, Moscow, ID, USA; ${ }^{4}$ Centre \\ for Research in Nanotechnology \\ and Sciences, IIT Bombay, Mumbai, \\ Maharashtra, India
}

\begin{abstract}
The localized surface plasmon resonance (LSPR) property of gold nanoparticles (GNP) has been exploited in a variety of optical sensor configurations including solution-based bioassays, paper-based colorimetric detection, surface-confined nanoparticle film/array-based sensing, etc. Amongst these, gold nanostructured films are of great interest because of their high stability, good reproducibility, robustness, and cost-effectiveness. The inherent optical characteristics of GNP, are attributed to parameters like size and shape (eg, nanospheres, nanorods, nanostars), eg, LSPR spectral location sensitivity to the local environment, composition (eg, gold-silver or silica-gold nanoshells), sensing volume, mesospacing, and multiplexing. These properties allow sensor tunability, enabling enhanced sensitivity and better performance of these biosensors. Ultrasensitive biosensor designs were realized using gold nanostructured films fabricated by bottom-up as well as top-down approaches. In this review, we describe the past, present, and future trends in the development of GNP-LSPRbased sensors, concentrating on both design (fabrication) and application. In the process, we have discussed various combinations of GNP size and shape, substrate, and application domains.
\end{abstract}

Keywords: localized surface plasmon resonance, gold nanoparticles, label-free optical biosensor

\section{Introduction}

Over the last few decades, progress in transducer fabrication technology coupled with an increase in understanding of biomolecular interactions has led rapid strides in biosensor development. Such ultrasensitive biosensors have leveraged on the exquisite specificity, affinity, and versatility of biomolecular interactions. A variety of biosensor matrices has been incorporated on various types of physicochemical transducers. Among the different types of transducers, optical biosensors have been studied extensively because of their potential advantages over the other sensing modes. ${ }^{1}$ Amongst these, sensors based on surface plasmon resonance (SPR) have evinced significant interest amongst researchers due to the fact that such detection systems neither require any fluorescent labels nor do they require light to pass through the analyte medium. ${ }^{1}$ In addition, the overall detection process is accelerated with the potential to detect multiple targets in an unknown, complex biological sample. ${ }^{2}$ As a result, a number of biochemical sensors have been explored on the basis of SPR properties of different metallic thin films. ${ }^{2,3}$

In parallel with advancements in SPR sensors, several researchers studied the plasmonic properties of gold colloids. The optical properties of gold colloids were empirically known for hundreds of years. Colloidal gold was used by ancient Romans
Correspondence: Soumyo Mukherji Department of Biosciences and Bioengineering, IIT Bombay, Powai, Mumbai 400 076, India Tel +912225767767

Fax +91 2225723480

Email mukherji@iitb.ac.in 
and during the medieval era for tinting glass. It was also popular among alchemists for some of its medicinal values. In a breakthrough study in 1857 , Faraday reported the formation of deep red solutions of colloidal gold by reduction of an aqueous solution of gold salt using phosphorus in carbon disulphide. ${ }^{4}$ Five decades later, in 1908, the nature of optical extinction and scattering by spherical noble metal nanoparticles was theoretically modeled by Mie, in one of the most widely cited articles in this sphere of science. ${ }^{5}$ According to this theory, the extinction spectrum of a spherical nanoparticle is expressed as the sum of a series of vector spherical harmonics of the electromagnetic fields of the incident wave, scattered wave, and the particle wave. Mie's theory also accounts for the field retardation effects observed when the particle size becomes comparable to the wavelength of the photon. Other approximation theories such as discrete dipole approximation ${ }^{6}$ and finite-difference time domain ${ }^{7}$ have been proposed to study the optical properties of nonspherical metallic nanoparticles. After the theoretical explanation of optical properties, metallic nanoparticles (eg, gold, silver) attracted researchers of all domains to explore their applications.

It is now well accepted that the plasmonic properties of metallic nanoparticles (eg, gold, silver) arise from localized surface plasmons (LSP) on the atoms of colloid surfaces caused by interaction with photons (Figure 1). ${ }^{8}$ This phenomenon is typically present only when the particle size is smaller than the wavelength of the incident light. The resonance frequency of LSP, ie, LSPR, in metallic nanoparticles is intrinsically the same characteristic as manifested in SPR, and the resonance frequency is determined by the complex dielectric function of the metal and the dielectric constant of the surrounding medium. ${ }^{9}$

Although both SPR and LSPR have been exploited equally for sensor development by measuring refractive index (RI) changes, nanoparticle-based LSPR sensors have a number of advantages over thin film-based SPR sensors, most of which will be apparent in the later sections of this

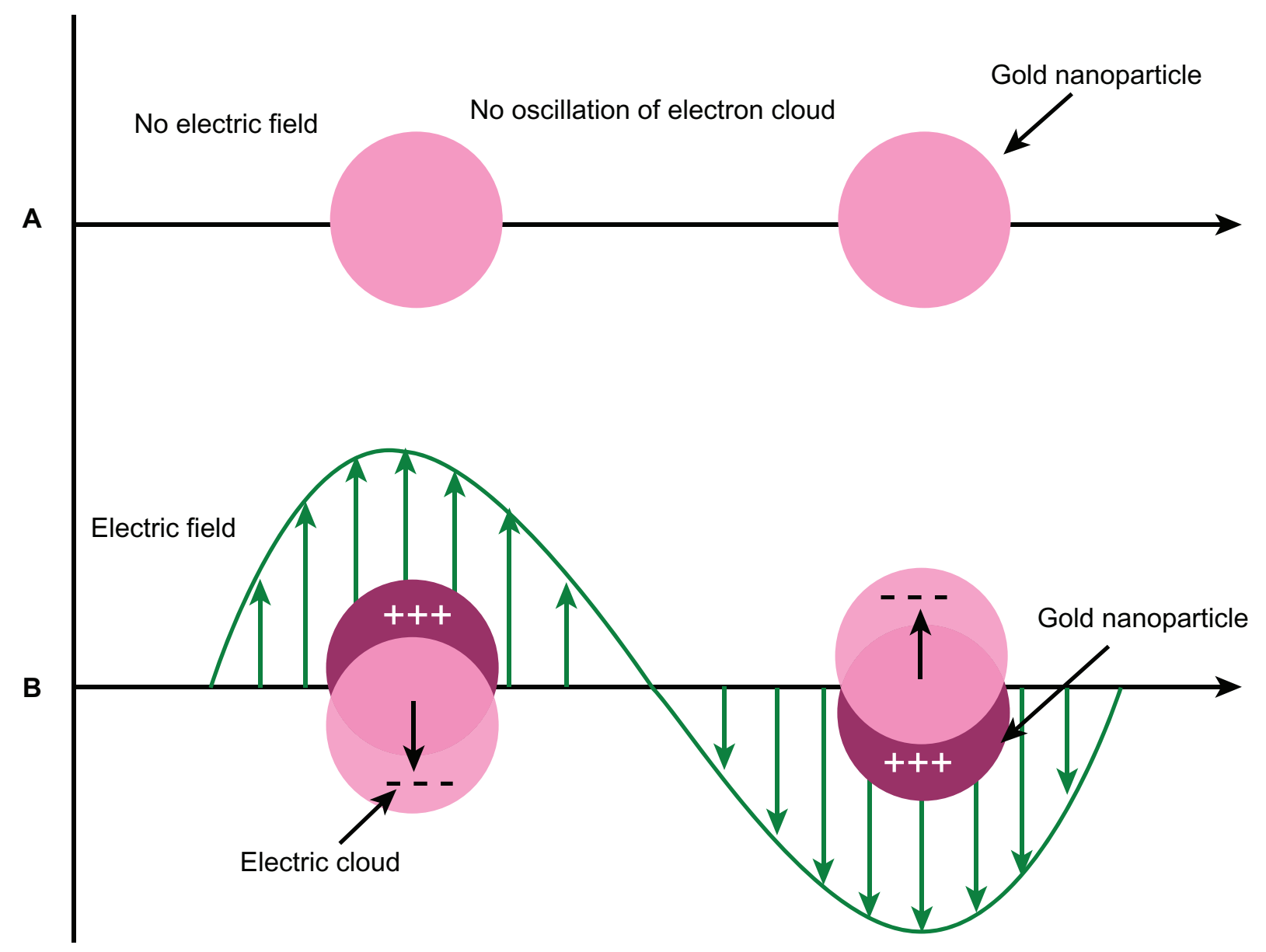

Figure I Effect of electric field on oscillations of conduction electrons of gold nanoparticles. 
article. However, it should be mentioned upfront that the instrumentation for such sensors is potentially easier than that for SPR-based sensors. Further, since the LSPR peak may be tuned or changed by changing size and shape of gold colloids, multiplexed sensing is possible using different gold colloids on a single sensor matrix. The configuration of these sensors also allows the detection of molecules of very low $(<1 \mathrm{kD})$ molecular weight, which is uncommon with thin-film SPR sensors. ${ }^{10}$ It has been seen that silver nanoparticles display sharper and more intense LSPR bands and thereby higher RI sensitivity than gold nanoparticles. However, the higher chemical stability of gold has resulted in a wider preference for this noble metal for biosensing applications.

The optical properties of GNP due to the LSP have been instrumental in the realization of several optical biosensor platforms. Two distinct classes of plasmonic biosensors have emerged. The first class of biosensors is based on localized field enhancement of electromagnetic signals interacting with LSP. This has been exploited in surface-enhanced Raman scattering, ${ }^{11,12}$ surface-enhanced fluorescence, ${ }^{13}$ and thin metal film SPR-based biosensors. ${ }^{14,15}$ The other class is based on the RI sensitivity of LSP, which has been utilized in the development of LSPR biosensors. ${ }^{9}$ With a suitable receptor immobilized on the surface of GNP, an LSPR sensor can detect target molecules even if the molecules do not have a spectral signature in the visible-NIR range.

Earlier, free gold colloid-based optical biosensors, ie, aggregation-based bioassays, were established for qualitative and quantitative determination of biomolecular interactions. ${ }^{16,17}$ By using this approach, researchers have been able to achieve attomolar to femtomolar sensitivity. ${ }^{18}$ However, uncertainty with respect to nanoparticle concentration during the multiple washing steps (to remove unbound analytes) and low shelf stability of gold colloids have resulted in a limited number of applications evolving from this technique. It may be noted that a number of factors (solvent, stabilizer, surfactant, $\mathrm{pH}$, etc) might affect the stability of the gold colloids. On the other hand, immobilized gold colloid-based sensing has shown immense potential to develop versatile sensors with enhanced performance, eg, stability, sensitivity, selectivity, reusability, and the ability to be multiplexed for complex analyte sensing. In the past few years, several excellent reviews have been published that discuss the experimental and theoretical aspects of nanometric particle optics as well as the use of metallic nanoparticles in sensing applications. ${ }^{8,19-25}$ This review complements those by discussing the fabrication and application of LSPR-based biosensors, with emphasis on immobilization of gold colloids. We discuss the characteristics of gold colloids (size, shape, and composition) that influence biosensor performance. We also review some recent advances in the construction of gold colloid-based LSPR biosensors and their applications in immunosensing, nucleic acid detection, and quantification of toxins.

\section{Synthesis strategies of gold colloid}

Numerous routes have been suggested to synthesize gold colloids with tunable plasmonic properties. The most common approach is the reduction of a metal salt in solution to form noble metal colloidal suspension. Size control is generally achieved by varying the molar ratio of the metallic salt and reducing agent. Some important strategies for synthesis of different types of gold colloids are summarized in Table 1.

The last decade has witnessed some top-down techniques such as electron beam lithography, ${ }^{46,47}$ focused ion beam lithography, ${ }^{48}$ nanosphere lithography (NSL) ${ }^{49}$ nanoimprint lithography, ${ }^{50,51}$ and soft interference lithography ${ }^{52}$ developed to fabricate gold nanostructures on a substrate. These techniques have provided greater control on size, shape, and interparticle spacing of gold nanostructures and hence proved their potential for fabricating microarrays. However, some of these techniques are very expensive compared to the direct use of capped gold colloids.

The assembly of gold colloids on solid sensor substrates is generally carried out by chemical binding and exploiting the high affinity of gold toward amino, cyano, and thiol functional groups. However, other strategies such as electrostatic interactions between oppositely charged surfaces and metallic nanoparticles have also been used. A self assembled layer of GNP yields an optically transparent monolayer, where the assembly is stabilized by the opposite forces of strong attractive colloid surface interactions and repulsive colloid-colloid electrostatic interactions. ${ }^{27,53,54}$

\section{Characteristics of gold colloids and their influence on sensor performance}

The LSPR properties of gold colloids are strongly dependent on their composition, size, shape, spatial arrangement, and $\mathrm{RI}$ of the dielectric medium around them. The environmental sensitivity of GNP was first demonstrated by Englebienne 1998, who fabricated a biosensor based on colorimetric detection. ${ }^{55}$ Later Okamoto et $\mathrm{al}^{56}$ showed that the absorbance of an immobilized monolayer of gold colloids was sensitive to RI of the surrounding solvent. In this section, we 
Table I Synthesis methods for different types of gold colloids

\begin{tabular}{|c|c|c|}
\hline Colloid types & Synthesis methods & References \\
\hline \multirow[t]{19}{*}{ Gold nanospheres } & Sodium citrate & Turkevich et $\mathrm{al}^{26}$ \\
\hline & reduction method & Grabar et $\mathrm{al}^{27}$ \\
\hline & Sodium borohydride & Brust et $\mathrm{al}^{28}$ \\
\hline & reduction method & \\
\hline & in biphasic system & \\
\hline & Modified Brust- & Hostetler et $\mathrm{al}^{29}$ \\
\hline & Schiffrin reaction & \\
\hline & Sodium borohydride & Jin et $\mathrm{al}^{30}$ \\
\hline & reduction method & Frederix et $\mathrm{al}^{31}$ \\
\hline & & Lin et $\mathrm{al}^{32}$ \\
\hline & Oleyl amine & Aslam et $\mathrm{al}^{33}$ \\
\hline & reduction method & \\
\hline & Glutamate & Sugunan et $\mathrm{al}^{34}$ \\
\hline & reduction method & \\
\hline & Gallic acid & Huang et $\mathrm{al}^{35}$ \\
\hline & reduction method & \\
\hline & Gamma irradiation & Anh et $\mathrm{al}^{36}$ \\
\hline & using sodium alginate & \\
\hline & as stabilizer & \\
\hline \multirow[t]{4}{*}{ Gold nanorods } & Seed-mediated & Jana et $\mathrm{al}^{37}$ \\
\hline & surfactant-directed & Nikoobakht and \\
\hline & & El-Sayed ${ }^{38}$ \\
\hline & & Sau and Murphy ${ }^{39}$ \\
\hline \multirow[t]{5}{*}{ Gold nanoshells } & Template-engaged & Sun and $\mathrm{Xia}^{40}$ \\
\hline & replacement reaction & \\
\hline & between silver & \\
\hline & nanoparticles (AgNP) & \\
\hline & and gold chloride & \\
\hline \multirow[t]{3}{*}{ Gold bipyramids } & Seed-mediated & Liu and \\
\hline & surfactant-directed & Guyot-Sionnest $^{41}$ \\
\hline & & Lee et $\mathrm{al}^{42}$ \\
\hline \multirow[t]{2}{*}{ Stars } & Seed-mediated & Nehl et $\mathrm{al}^{43}$ \\
\hline & surfactant-directed & \\
\hline \multirow[t]{2}{*}{ Cubes } & Seed-mediated & Sau and Murphy ${ }^{39}$ \\
\hline & surfactant-directed & \\
\hline \multirow[t]{2}{*}{ Branched } & Seed-mediated & Sau and Murphy ${ }^{39}$ \\
\hline & surfactant-directed & \\
\hline \multirow[t]{4}{*}{ Nanodecahedra } & Seed-mediated, & Sánchez-|glesias et al ${ }^{44}$ \\
\hline & ultrasound-induced & Pastoriza-Santos et $\mathrm{al}^{45}$ \\
\hline & reduction by $\mathrm{N}, \mathrm{N}$ - & \\
\hline & dimethylformamide & \\
\hline
\end{tabular}

have focused on the characteristics of gold colloids, which have been exploited in development of biosensors by various groups of researchers.

\section{Size and shape}

It has been mentioned earlier that the size and shape of gold colloids can be controlled by slight modification of reaction protocol, reaction conditions, and molar concentrations of reactants. ${ }^{39,41}$ This has an impact on the spectral signature of the gold colloids in the UV-vis-NIR range and has led to the development of a variety of biosensors. A change in size and shape of gold colloids modulates the wavelength of maximum extinction $\left(\lambda_{\max }\right)$ and the bandwidth. It has been observed that a red shift in the peak wavelength as well as an increase in bandwidth occurs with an increase in the particle size. ${ }^{57}$ This is largely due to phase-retardation effects in larger nanoparticles and the contribution of scattering to the extinction coefficient. For larger nanoparticles, contribution of scattering to the extinction spectrum dominates that of absorption and results in an increase in the extinction intensity, a red shift in $\lambda_{\max }$, and an increase in the bandwidth. In addition, increased polydispersity in a collection of larger GNP manifests itself in a broadening of the extinction spectrum. ${ }^{58}$

In some of the recent studies, researchers have optimized the size and shape of gold colloids to develop high performance LSPR sensors. For example, Nath and Chilkoti found that sensors fabricated with $39 \mathrm{~nm}$ diameter spherical gold nanoparticles (sGNP) exhibited maximum sensitivity to bulk RI change..$^{57}$ These researchers suggested that the fractional coverage of sensor surface increased as a function of the particle size, and for particles of $39 \mathrm{~nm}$ size, it was more than 1.5 times as compared to $12 \mathrm{~nm}$ particle size.

In the past few years, gold colloids of different shapes have been created, including spheres, rods, stars, crescents, decahedra, and bipyramids (Table 1). Some of these shapes have displayed much higher sensitivity toward the bulk RI changes than nanospheres. This can be attributed to the shape-related plasmonic properties that are tunable from UV-visible to NIR range. It has also been suggested that the sensitivity of the plasmon band to RI changes is solely a function of the wavelength of the plasmon band for particles of a given composition and that nanoparticles with a plasmon band at higher wavelengths are more sensitive to their local environment than those at shorter wavelengths. ${ }^{59}$ In addition to greater RI sensitivity, higher LSPR wavelength avoids background absorption and scattering due to endogenous chromophores from biological mixture serum, blood, etc. This indicates that nanospheres may have the least sensitivity amongst nanoparticles of different shapes but constant volume.

Gold nanorods (GNR) exhibit stronger and tunable absorption (corresponding to the longitudinal plasmon oscillation) and the possibility of unidirectional plasmon propagation. ${ }^{60,61}$ GNR exhibit two distinct plasmon bands, one associated with the transverse $(\lambda=520 \mathrm{~nm})$ mode and the other with the longitudinal mode (usually $\lambda \geq 600 \mathrm{~nm}$ ). This property of GNR has motivated researchers to take interest in controlled assembly of GNR into functional architectures as well as for analyte-sensing applications. Marinakos and colleagues ${ }^{62}$ observed that bulk RI senstivity of GNR 
was more than four times that of GNP. Gold nanorods (aspect ratio [AR] 2.25)-based LSPR chips showed wavelength sensitivity of $252 \mathrm{~nm} / \mathrm{RIU}$, while the sensitivity of LSPR chips fabricated from $39 \mathrm{~nm}$ diameter sGNP was $60 \mathrm{~nm} / \mathrm{RIU}$. On comparing different AR it was found that RI sensitivity increased as a function of $A R$ and reached $366 \mathrm{~nm} / \mathrm{RIU}$ sensitivity for GNR with mean AR = 5.2. ${ }^{63} \mathrm{Jain}$ and colleagues have also demonstrated experimentally and theoretically that the longitudinal plasmon wavelength was highly sensitive to change in the dielectric properties of the surroundings and that the sensitivity increases as the AR of the nanorods increases. ${ }^{61}$

Recently, gold bipyramids (GBP) have been employed to develop LSPR sensor chips. ${ }^{42}$ This sensor showed higher figure of merit (FOM), ie, sensitivity divided by the LSPR full width at half-maximum, values of 3.5-3.9 compared to GNR substrates. It was attributed to the monodispersity of GBP and sharp tips with a potential for strong field enhancement. Similar to GNR-based sensors, sensitivity of these GBPbased sensors increased with mean AR. GBP with AR of 2.5 exhibited $289 \mathrm{~nm} / \mathrm{RIU}$ sensitivity, while AR of 3.2 resulted in $381 \mathrm{~nm} / \mathrm{RIU}$ sensitivity.

Nehl et al synthesized star-shaped GNPs using a seed-mediated surfactant-directed method. ${ }^{43}$ Spectroscopic measurements revealed that these nanoparticles exhibited multiple plasmon resonances resulting in polarization-dependent scattering with multiple spectral peaks, which correspond to the different tips on the star-shaped structure. The plasmon resonances were also found to be extremely sensitive to the local dielectric environment. The authors reported that individual gold nanostars displayed $1410 \mathrm{meV} / \mathrm{RIU}$ dielectric sensitivity, and the FOM for these particles was 10.7, which was higher than that previously observed for any other colloid.

\section{Composition}

Similar to the different anisotropic GNP, researchers have been able to produce gold colloids of different composition, eg, gold nanoshells (GNS). The plasmonic properties of GNS can be tuned systematically in the NIR region of the spectrum (700-1300 $\mathrm{nm}$ ) by changing the relative dimensions of the core and shell layers. Thus, the LSPR peaks of these GNS are considerably red-shifted as compared to sGNP having the same dimensions. In addition, GNS exhibit high RI sensitivity compared to sGNP of similar size. For example, GNS (mean size $=50 \mathrm{~nm}$; wall thickness $=4.5 \mathrm{~nm}$ ) showed $408.8 \mathrm{~nm} / \mathrm{RIU}$ sensitivity, which was $\sim 7$ times more when compared to sGNP with roughly the same dimensions. ${ }^{40}$
The enhanced sensitivity is due to the thin walls of GNS and changes in the dielectric property of hollow nanostructures. It has also been suggested that the sensitivity of GNS (silicagold) increases largely with overall nanoparticle size and to a lesser extent with core/shell ratio. For silica-gold nanoshells, $555.4 \mathrm{~nm} / \mathrm{RIU}$ sensitivity has been observed, which is similar to or greater than the sensitivities achieved with other gold colloid types. ${ }^{64}$

\section{Sensing volume}

An important consideration in the design of an LSPR sensor is the quantification of distance from the surface of the nanoparticles at which the particle can no longer detect a change in the RI. As all receptor-analyte binding events occur within a short, but variable, distance of the nanoparticlesolution interface, this distance must be commensurate with the dimension of the receptor-analyte pair to maximize sensitivity. The range of this effective analytical volume depends on the size and shape of gold colloids.

It is known that the electromagnetic field of nanoparticles decays with the distance from the surface and is dependent on the size and anisotropy of the nanoparticles. Okamoto et $\mathrm{al}^{56}$ experimentally observed that the peak absorbance and the resonance wavelength are highly sensitive to variations in the thickness of additional layers up to $\sim 10 \mathrm{~nm}$, beyond which the response seems to saturate. Larger nanoparticles possess greater sensing volume compared to smaller nanoparticles although the change in sensing distance is not linearly related to the size of the GNP. It has been demonstrated that sGNP of $12 \mathrm{~nm}$ size could detect a RI change up to $24 \mathrm{~nm}$ away from the nanoparticle surface, whereas $39 \mathrm{~nm}$-sized sGNP could detect RI change at a distance greater than $40 \mathrm{~nm} .{ }^{57}$ Similarly, GNR (74 $\mathrm{nm}$ in length and $33 \mathrm{~nm}$ in diameter, $A R=2.25$ )-based LSPR chips could detect a RI change to a distance of at least $40 \mathrm{~nm}$ with the most sensitivity in the first $10 \mathrm{~nm}$ of their surface. ${ }^{62}$ Therefore, binding of a large antigen to an antibody that is immobilized on the nanoparticle can be detected using comparatively larger nanoparticles.

\section{Mesospacing}

Controlled lateral spacing between GNP on a sensor surface, ie, mesospacing, plays a vital role for precise control of the sensor performance. Interparticle spacing affects the sensitivity and the electric field distribution around the nanoparticles. For plasmonic wavelength shift-based assays, it has been proved experimentally and by computational modeling that greater average interparticle spacing results in higher wavelength sensitivity and larger sensing volume due to a wider 
spread of intensified electric field.$^{65}$ Nath and Chilkoti found that the extinction sensitivity of LSPR sensors (based on the extinction measurements at a single wavelength) increased linearly as a function of the surface density of the immobilized nanoparticles on the sensor substrates and approaches saturation. ${ }^{57}$ It can be observed from both these studies that the sensitivity and sensing distance depend crucially on the surface density or surface coverage of the nanoparticles.

\section{Multiplexing}

Currently, microarrays and microchips are gaining importance in the present age of multiplexed sensing schemes. Gold nanostructure-based biosensing platforms have shown immense potential in the development of multiplexed biosensors due to their tunable plasmonic properties. Researchers have developed a multithroughput LSPR (MLSPR) chip by immobilizing five kinds of GNR (differing in AR) on silanized glass slides ${ }^{66}$ These sensor chips exhibited five plasmon peaks implying a possibility to detect five acceptor-ligand interactions simultaneously in the wavelength range from 530 to $940 \mathrm{~nm}$ (Figure 2). Further, the authors successfully used MLSPR sensor to detect two different antibody-antigen interactions simultaneously.

Recently, researchers fabricated hybrid sensor chips using three different types of functionalized metallic nanoparticles that exhibit LSPR peaks at different wavelengths. ${ }^{67}$ The three types of metallic nanoparticles used in this study were silver nanoparticles, sGNP, and nanoshells (silver-gold) with their corresponding LSPR peaks at 427, 534, and $772 \mathrm{~nm}$, respectively. These hybrid chips were shown to be able to detect nine types of volatile organic compounds with various functional groups, demonstrating their applicability toward detection of complex analytes with multiple molecules of interest.

\section{Biosensor applications based on LSPR of gold colloids}

Decades ago, significant amount of research in gold colloids and functionalization of such colloids for biosensing resulted in sensing systems using aggregation-based assays. ${ }^{16,17}$ These gold colloid assays were popular because of their low cost and ease of use. Over the past decade, the transduction and signal capture from LSPR-based biosensors have evolved through the research of several groups around the world. These nanobiosensors have proved their versatility in various applications such as clinical and environmental monitoring, biotechnology, and food safety. These sensors have been widely employed to monitor a broad range of analyte-surface binding interaction such as adsorption of small molecules, ligand-receptor interactions, antibody-antigen interactions,
DNA and RNA hybridization, protein-DNA interaction, biomarkers, toxin detection, etc. Different types of transducer designs and their fabrication protocols have been proposed along with claims toward their potential advantages. Among these, most of the designs are in the form of chips, while others include fiber optic probes, lab-on-chip integrated with microfluidic, and cuttlebone-derived matrix. Applying the LSPR phenomenon of gold colloids in different sensor designs, researchers have demonstrated the detection of some medically relevant analytes in clinical samples at picomolar level. In this section, we have focused on the recent developments and the applications of LSPR biosensors. Although some research groups are still engaged in developing costeffective in vitro diagnostic strips, ${ }^{68,69}$ we have excluded such types of qualitative bioassays from this review.

\section{Immunosensor applications}

Gold colloid-based LSPR sensors have been used for quantification of a variety of analytes using antigen-antibody interactions (Table 2). Chilkoti's group fabricated nanoSPR chips by exploiting the LSPR properties of sGNP and GNR. ${ }^{57,62,70}$ These chips have shown good sensitivity for immunobiosensor applications. After immobilizing biotin on the sGNP of diameter $39 \mathrm{~nm}$, these nano-SPR chips were able to detect $0.83 \mathrm{nM}$ streptavidin. When GNR (AR 2.25) were used in nano-SPR chips, the detection limit of $94 \mathrm{pM}$ was achieved, which was much lower than that of sGNP. The GNR-anchored nano-SPR chips exhibited LSPR peaks in the NIR region. These biotin-functionalized LSPR chips were employed for bioassays of streptavidin in serum sample. The minimum detection limit of $19 \mathrm{nM}$ that was achieved was possible due to lack of interferences in the NIR region by the carrier fluid (viz, serum). Further, the same group proposed the use of a single GNR as a plasmonic transducer for the detection of biomolecular interactions. ${ }^{89,90}$ The lowest streptavidin concentration that was experimentally measured was $100 \mathrm{pM}$, which induced a mean resonant wavelength shift of $0.59 \mathrm{~nm}$. Analytical modeling of the same proved that the predicted minimum detection limit is 18 streptavidin molecules for this sensor, which was in good agreement with the experimental results. ${ }^{90}$ In another study, GNR of higher AR ( 5.2) were used to fabricate immunosensor chips. ${ }^{63}$ These chips displayed $25 \mathrm{ng} / \mathrm{mL}\left(4.2 \times 10^{-10} \mathrm{M}\right)$ limit of detection for streptavidin, which was lower than those with sGNP. Association equilibrium constant $(K)$ value was obtained as $1.2 \times 10^{7} \mathrm{M}^{-1}$ for biotin-streptavidin binding, which is equal to the typical binding constant. In a recent study, researchers have been able to achieve a linear equation between the 


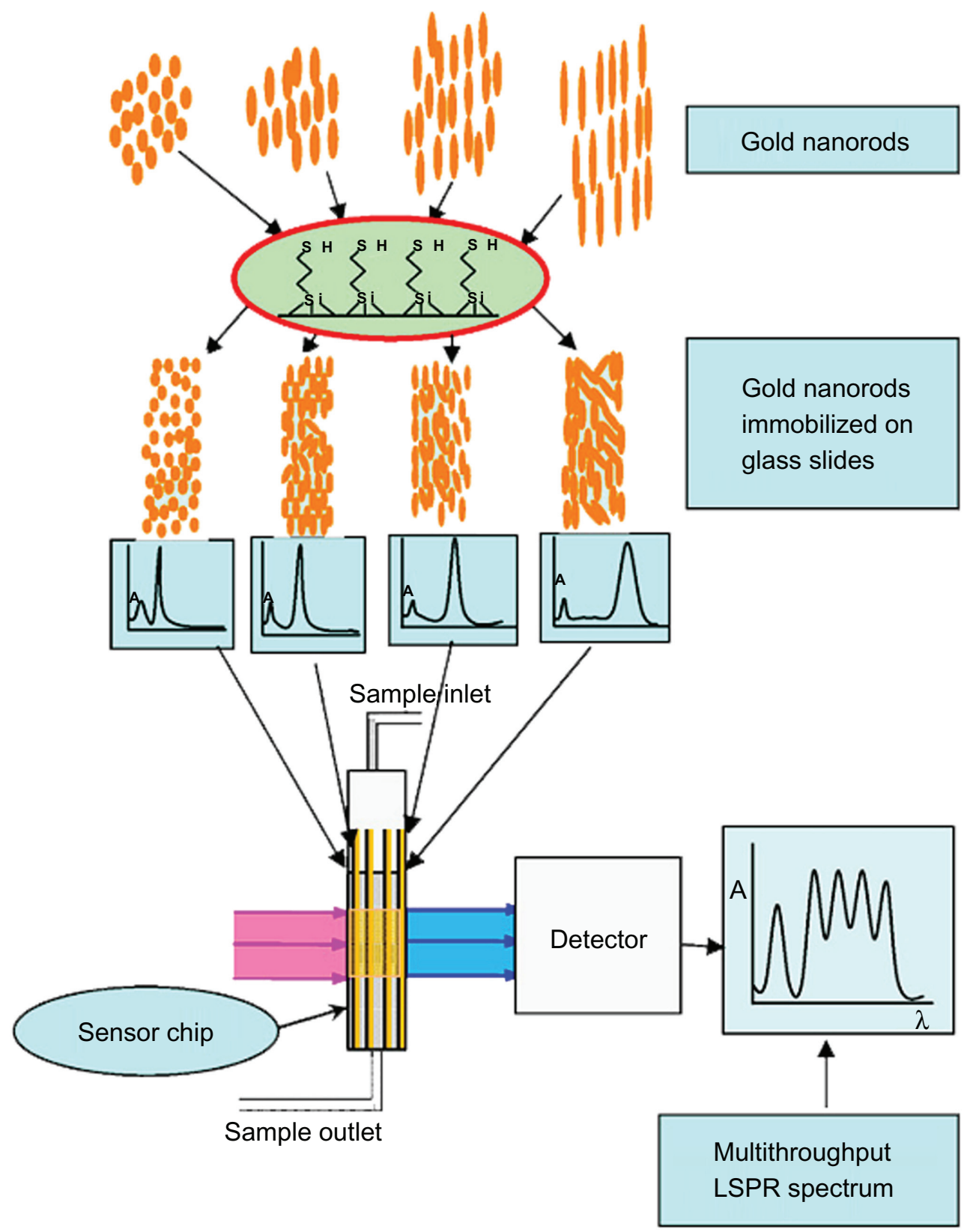

Figure 2 Scheme of multithroughput localized surface plasmon resonance.

Copyright (C) 2009, Elsevier. Reproduced with permission from Huang H, He C, Zeng Y, et al. A novel label-free multi throughput optical biosensor based on localized surface plasmon resonance. Biosens Bioelectron. 2009;24:2255-2259.

Abbreviations: $\lambda$, wavelength; A, absorbance; $\mathrm{SH}$, Thiol groups; Si, silicon.

concentration of antigen and the intensity of the longitudinal plasmonic band of GNR. ${ }^{91}$ These LSPR chips detected 0.1 $\mathrm{pM}$ of anti-goat IgG using goat IgG as a probe.

Gold nanorods are commonly synthesized by a seedmediated, surfactant-directed method. ${ }^{37,38}$ The most commonly used surfactant is cetyl trimethylammonium bromide (CTAB), which acts as both the source of anisotropic growth and the stabilizer. Due to the presence of CTAB, further chemical manipulation of the gold colloids becomes more complicated than that of classic citrate-stabilized gold colloids. Hafner's group suggested PEGylation of the nanorods to displace CTAB. ${ }^{79,92}$ These PEGylated GNR were found to be stable in solution. In addition, their bioconjugation is easier compared to CTAB-protected GNR, and processing of these nanorods on the sensor substrates leads to well-ordered films (Figure 3). The PEGylated GNR (AR 3.3)-anchored LSPR chips have been demonstrated for the detection of anti-rabbit IgG using rabbit IgG as the probe moiety. ${ }^{79}$ The immunoreaction was monitored through shifts in the LSPR spectral extinction peak. The limit of detection of this sensor 
Table 2 Immunosensors based on localized surface plasmon resonance of gold colloids

\begin{tabular}{|c|c|c|c|c|c|}
\hline Gold colloid types & Probe moieties & Analytes & Limits of detection & Device types & References \\
\hline sGNP (I3.4 nm) & Biotin & Streptavidin & $16 \mathrm{nM}$ & Chip & Nath and Chilkoti ${ }^{70}$ \\
\hline sGNP $(8.4 \mathrm{~nm})$ & Biotin & Streptavidin & $9.8 \times 10^{-11} \mathrm{M}$ & Optical fiber & Cheng and $\mathrm{Chau}^{71}$ \\
\hline sGNP (39 nm) & Biotin & Streptavidin & $0.83 \mathrm{nM}$ & Chip & Nath and Chilkotij ${ }^{57}$ \\
\hline sGNP $(40 \mathrm{~nm})$ & Glucose & Con $\mathrm{A}$ & $1.9 \mathrm{nM}$ & Chip & Morokoshi et al ${ }^{72}$ \\
\hline $\begin{array}{l}\text { GNS (silica-gold) } \\
100-30 \mathrm{~nm}\end{array}$ & $\begin{array}{l}\text { Anti-fibrinogen } \\
\text { antibody }\end{array}$ & Fibrinogen & $10 \mathrm{ng} / \mathrm{mL}$ & Chip & Endo et $\mathrm{al}^{73}$ \\
\hline sGNP $(20 \mathrm{~nm})$ & $\begin{array}{l}\text { Phenylboronic acid- } \\
\text { carrying polymer } \\
\text { brush }\end{array}$ & Ovalbumin & $100 \mathrm{nM}$ & Chip & Kitano et a ${ }^{14}$ \\
\hline GNR (AR 5.2) & Biotin & Streptavidin & $42 \mathrm{nM}$ & Chip & Chen et $\mathrm{a}^{63}$ \\
\hline sGNP $(16 \mathrm{~nm})$ & Glucose & Con A & $0.1 \mathrm{nM}$ & Chip & Guo et $\mathrm{a}^{75}$ \\
\hline $\begin{array}{l}\text { GNS (silica-gold) } \\
100-30 \mathrm{~nm}\end{array}$ & Casein & Anti-casein & $10 \mathrm{ng} / \mathrm{mL}$ & Chip & Hiep et $\mathrm{a}^{76}$ \\
\hline GNR (AR 2.25) & Biotin & Streptavidin & 94 pM & Chip & Marinakos et $\mathrm{a}^{62}$ \\
\hline $\begin{array}{l}\text { GNS (silica-gold) } \\
(100-30)\end{array}$ & $\begin{array}{l}\text { Anti-mouse IL-2 } \\
\text { antibody }\end{array}$ & IL-2 & $10 \mathrm{pg} / \mathrm{mL}$ & Chip & Endo et $\mathrm{al}^{77}$ \\
\hline $\begin{array}{l}\text { Gold capped oxide } \\
\text { nanostructures (15 nm) }\end{array}$ & Aptamer & Thrombin & I nM & Chip & Kim et $\mathrm{al}^{18}$ \\
\hline GNR (AR 3.3) & Rabbit IgG & $\begin{array}{l}\text { Goat anti-rabbit } \\
\lg G\end{array}$ & $\mathrm{I} \mathrm{nM}$ & Chip & Mayer et $\mathrm{al}^{79}$ \\
\hline GNR (AR 2.25) & Biotin & Streptavidin & I nM & Chip & Nusz et $a^{89}$ \\
\hline $\begin{array}{l}\text { GNS (silica-gold) } \\
\text { I I0-25 nm }\end{array}$ & Biotin & Streptavidin & $3 \mu \mathrm{g} / \mathrm{mL}$ in blood & Chip & Wang et $\mathrm{a}^{80}$ \\
\hline sGNP (5 nm) & Biotin & Streptavidin & $0.01 \mu g / \mathrm{mL}$ & Chip & Kajiura et $a^{81}$ \\
\hline GBP (AR 3.2) & Rabbit IgG & $\begin{array}{l}\text { Goat anti-rabbit } \\
\lg G\end{array}$ & $\mathrm{I} \mathrm{nM}$ & Chip & Lee et $\mathrm{al}^{42}$ \\
\hline sGNP $(20 \mathrm{~nm})$ & Biotin & Antibiotin & $100 \mathrm{ng} / \mathrm{mL}$ & Chip & Li et $\left.a\right|^{82}$ \\
\hline sGNP $(43 \mathrm{~nm})$ & Biotin & Antibiotin & $5 \mu \mathrm{g} / \mathrm{mL}$ & $\begin{array}{l}\text { Micro-fluidic } \\
\text { integrated chip }\end{array}$ & Huang et $\mathrm{a}^{83}$ \\
\hline GNR & Goat IgG & Anti-goat IgG & $0.1 \mathrm{pM}$ & Chip & Huang et $\mathrm{al}^{91}$ \\
\hline sGNP $(43 \mathrm{~nm})$ & Biotin & Antibiotin & $270 \mathrm{ng} / \mathrm{mL}$ & Chip & Huang et al ${ }^{84}$ \\
\hline sGNP $(40 \mathrm{~nm})$ & HIgG & Anti-HIgG & $0.12 \mu \mathrm{g} / \mathrm{mL}$ & Optical fiber & Sai et $\mathrm{a}^{85}$ \\
\hline sGNP $(25 \mathrm{~nm})$ & Anti-human IgG & Human-IgG & $\mathrm{I} \mu \mathrm{g} / \mathrm{mL}$ & Chip & Bi et $\left.a\right|^{86}$ \\
\hline sGNP $(50 \mathrm{~nm})$ & $5-\mathrm{FU}$ & Anti-5-FU & $10 \mathrm{ng} / \mathrm{ml}$ & Chip & Hiep et $\mathrm{a}^{87}$ \\
\hline sGNP $(50 \mathrm{~nm})$ & Biotin & Streptavidin & $100 \mathrm{ng} / \mathrm{mL}$ & Chip & Hiep et a ${ }^{87}$ \\
\hline sGNP $(23 \mathrm{~nm})$ & Rabbit IgG & Anti-rabbit lgG & $11.1 \mathrm{ng} / \mathrm{mL}$ & Optical fiber & Shao et a ${ }^{88}$ \\
\hline
\end{tabular}

Abbreviations: sGNP, spherical gold nanoparticles; GNS, gold nanoshells; GNR, gold nanorods; GBP, gold bipyramids; IgG, immunoglobulin G; IL, interleukin-2; Con A, concanavalin A.

was observed to be $1 \mathrm{nM}$. The equilibrium constant, $K_{e q}$, was found to be $2.0 \times 10^{9} \mathrm{M}^{-1}$, which is the typical equilibrium constant for an antigen-antibody interaction.

Similar to GNR, GNS exhibit LSPR peaks in the NIR range, depending upon their size and core to shell ratio. This is useful for chip-based bioassays of blood samples since most of the blood constituents display absorbance in the UV-visible range and not in the NIR region. GNS-based chips have been designed to quantify biotin-streptavidin interactions in diluted whole blood (Figure 4). ${ }^{80}$ Using LSPR peak wavelength at $730 \mathrm{~nm}$, the sensors displayed a detection limit of $3 \mu \mathrm{g} / \mathrm{mL}$ with a wide dynamic range (3-50 $\mu \mathrm{g} / \mathrm{mL})$.

Recently, GBP have been employed to fabricate LSPR chips in order to exploit their high bulk RI sensitivity. ${ }^{42}$
During real time kinetic studies, at $1 \mathrm{nM}$ concentration, the extinction peak shifted at a rate of $4.0 \times 10^{-5} \mathrm{~nm} / \mathrm{sec}$, and at $10 \mathrm{nM}$, the rate increased to $5.5 \times 10^{-4} \mathrm{~nm} / \mathrm{sec}$. These bipyramid peak shift rates were larger than those using nanorods $\left(2.1 \times 10^{-5}\right.$ and $2.1 \times 10^{-4} \mathrm{~nm} / \mathrm{sec}$, respectively $)$ by a factor of two. An immunoassay sensitivity constant was found to be $\mathrm{K}_{\mathrm{LSPR}}=0.01 \mathrm{~nm} \cdot \mu \mathrm{m}^{2}$ for GBP.

Tamiya's group fabricated core-shell nanostructured LSPR chips, using silica nanoparticle as the "core", and the outer "shell" was constructed by depositing a gold layer (Figure 5). ${ }^{73,76,77,93}$ After biofunctionalization, these LSPR chips have been used for the detection of a variety of analytes. By using anti-fibrinogen antibody-immobilized LSPR biochips, a $10 \mathrm{ng} / \mathrm{mL}$ detection limit of fibrinogen was achieved. These biochips have been adapted for multiarrays 


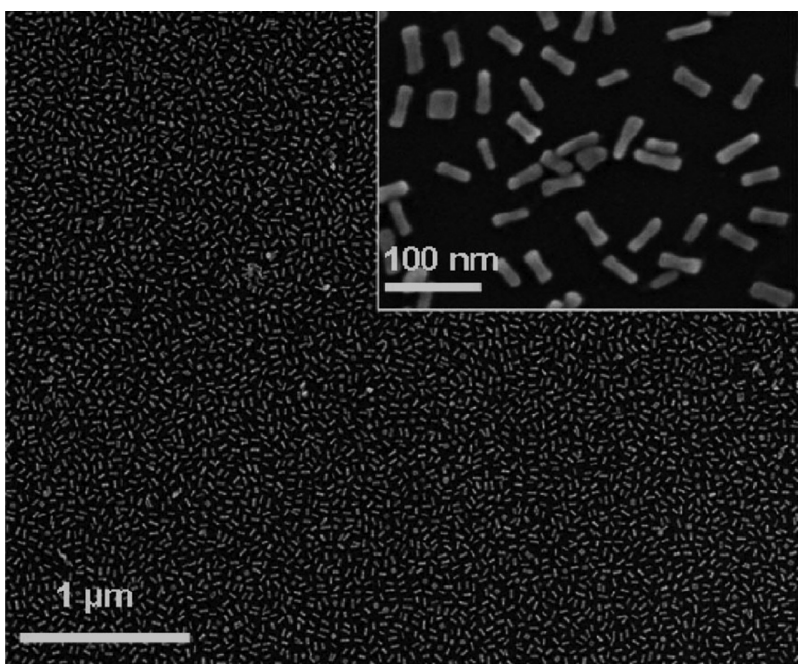

Figure 3 Scanning electron microscopy of films of PEGylated gold nanorods. Copyright (C) 2008, American Chemical Society. Reproduced with permission from Mayer KM, Lee S, Liao H, et al. A label-free immunoassay based upon localized surface plasmon resonance of gold nanorods. ACS Nano. 2008;2:687-692.

applications, for screening of bimolecular interactions. ${ }^{93}$ Parallel biomolecular detection using immunoglobulins (IgA, IgD, IgG, IgM), C-reactive protein, and fibrinogen was demonstrated. These multianalyte sensor chips achieved a detection limit of $100 \mathrm{pg} / \mathrm{mL}$. Later, this chip was modified to develop a casein immunosensor after immobilizing anti-casein antibody ${ }^{76}$ Under optimum conditions, the detec- tion limit of the casein immunosensor was determined to be $10 \mathrm{ng} / \mathrm{mL}$. Recently, these chips were further employed to detect specific reactions between the antibodies and the cell metabolite, IL-2. ${ }^{.7}$ In this case, the detection limit was $10 \mathrm{pg} / \mathrm{mL}$. Further, the researchers demonstrated the timecourse analysis of cell metabolism using the isolated cells from mouse thymus.

Advancing the applications of core-shell gold nanostructures, Tamiya's group fabricated an innovative sensing nanostructure, which exhibited a phenomenon termed as interference localized surface plasmon resonance (iLSPR), and used it for configuring sensor chips. ${ }^{78,87,94-96}$ This iLSPR was based on plasmonic GNP with photonic thin-film multilayers of porous aluminium oxide and aluminium (Al) on a substrate. In this iLSPR design, the high reflection $\mathrm{Al}$ substrate and the gold-nanoparticle layer caused multiple interactions of the incident light with the nanostructure similar to a Fabry-Perot resonator. These iLSPR chips have shown the capability of simultaneous monitoring of the changes in both the LSPR and the interferometric characteristics. Initially, these sensors were used for the detection of thrombin, using a sandwich-type assay. Two different aptamers were used, which bind to different sites of thrombin. The limit of detection was found to be $1 \mathrm{nM}$. More recently, Hiep et al ${ }^{87}$ demonstrated specific interaction

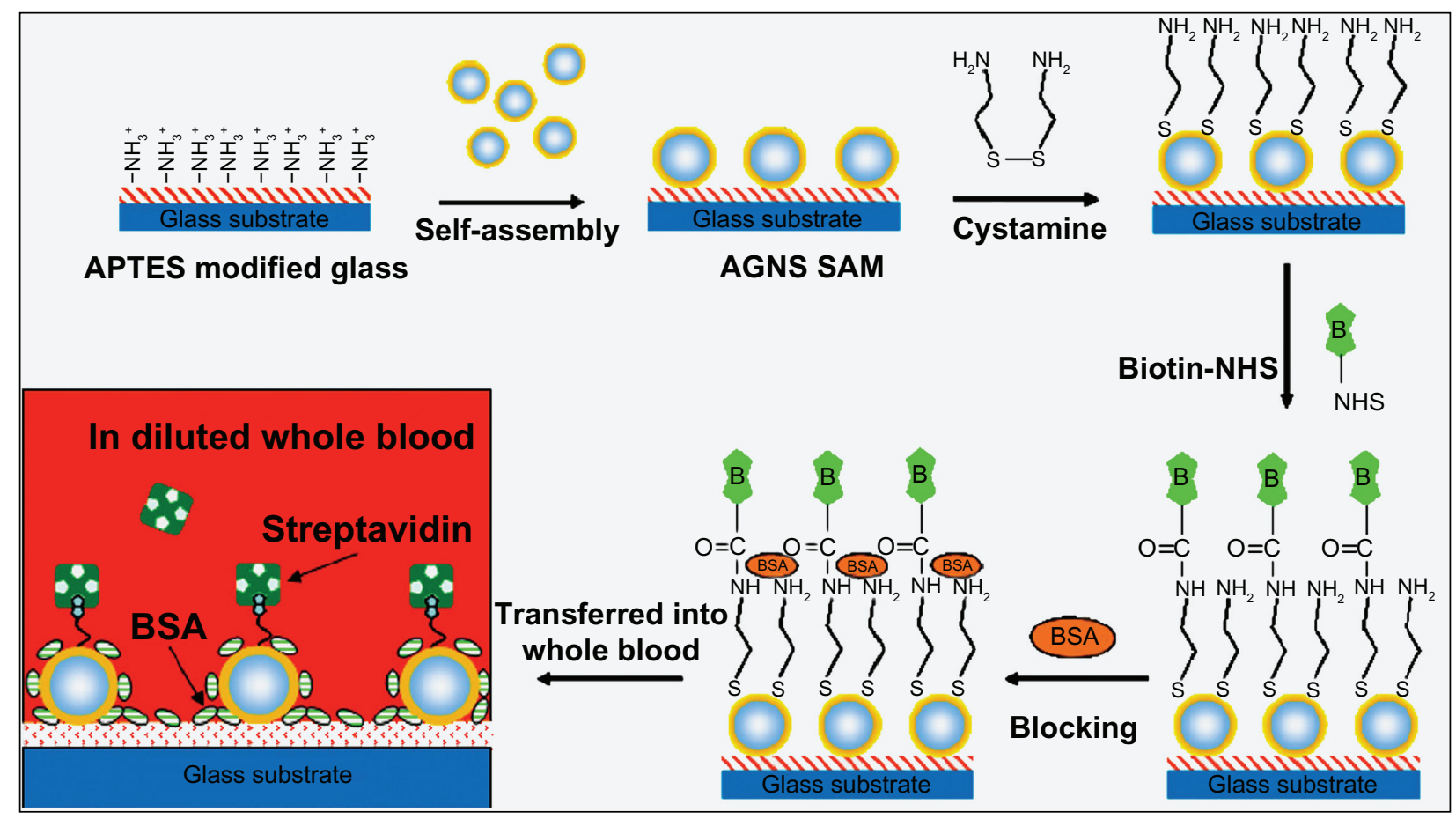

Figure 4 Schematic of fabrication process of the gold nanoshell self-assembled monolayers and the analysis of streptavidin in diluted blood sample.

Copyright @ 2008, Elsevier. Reproduced with permission from Wang Y, Qian W, Tan Y, Ding S. A label-free biosensor based on gold nanoshell monolayers for monitoring biomolecular interactions in diluted whole blood. Biosens Bioelectron. 2008;23: I I66-II 70.

Abbreviations: APTES, 3-aminopropyltrimethoxysilane; AGNS, silver-gold nanoshell; SAM, self-assembled monolayer; NHS, N-hydroxy succinimide. 


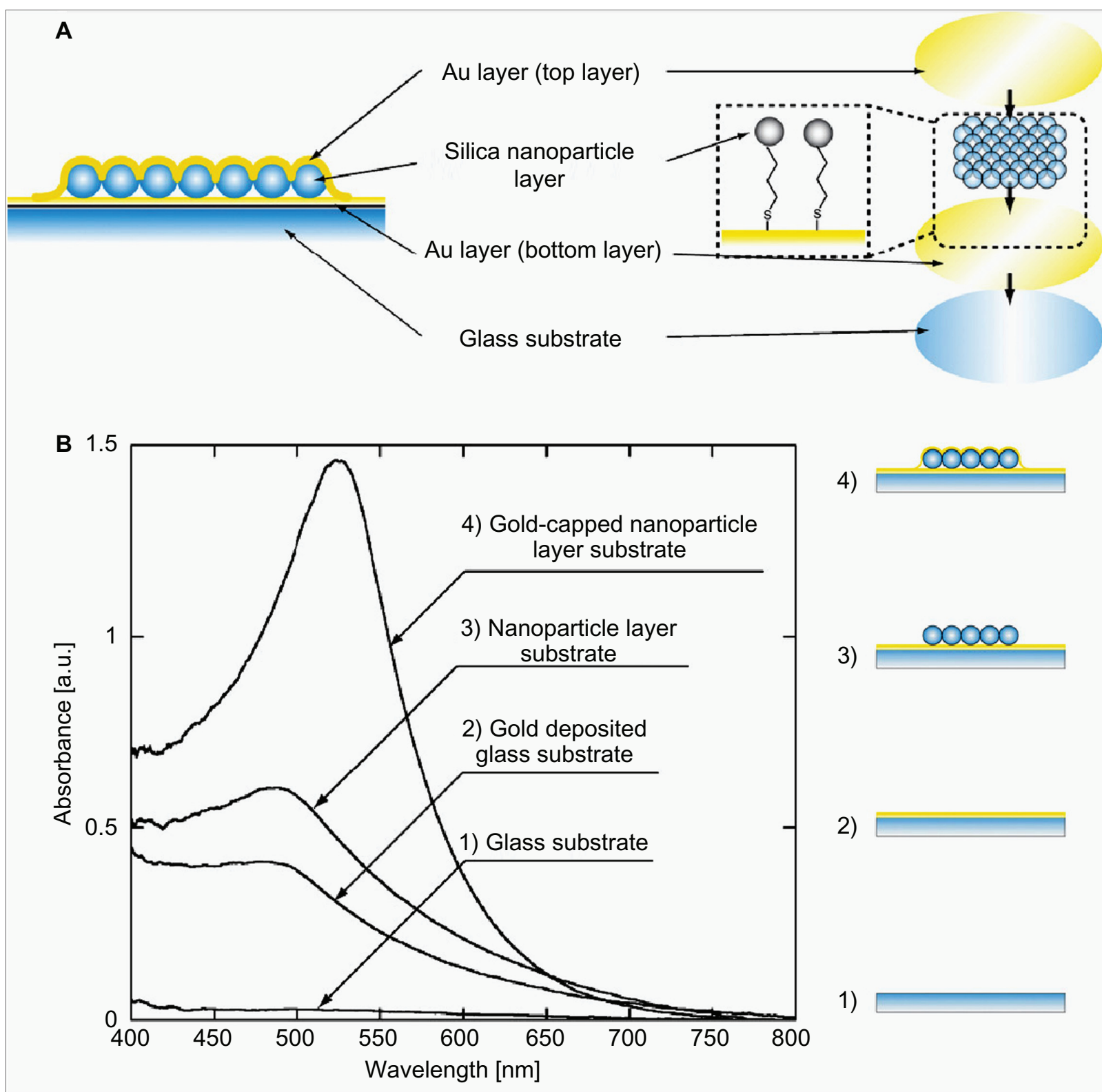

Figure 5 A) Schematic representation of core-shell (silica-gold) nanostructures on the glass substrate. Furthermore, the gold (Au) layer was formed on the nanoparticle layer using thermal evaporation. B) Optical characteristics of the gold-capped nanoparticle layer substrate.

Copyright () 2008, Elsevier. Reproduced with permission from Endo T, Yamamura S, Kerman K, Tamiya E. Label-free cell-based assay using localized surface plasmon resonance biosensor. Anal Chim Acta. 2008;614:182-189.

of biomolecules including biotin, avidin, and 5-fluorouracil (5-FU) and its antibody, anti-5-fluorouracil (anti-5-FU). This iLSPR biosensor was able to detect nanogram level of proteineous analytes.

The RI sensitivity of LSPR chips has been improved by three-dimensional GNP assemblies on the substrates. ${ }^{88}$ Exploiting this innovative approach, recently three-dimensional LSPR chips have been fabricated by layer-by-layer deposition of GNP and mercaptosilanized multiwalled carbon nanotubes (MWCNT) on a glass substrate. ${ }^{92}$ Mercaptosilanized MWCNT acted as a three-dimensional linker to assemble the GNP and also provided a large surface area and multiple binding sites. This sensor matrix allows high accessibility of target molecules due to the microporous nature of MWCNT. These three-dimensional chips showed 20 times higher sensitivity than the two-dimensional monolayer chips for streptavidin $(0.5 \mathrm{nM})$ and anti-human serum albumin (3.33 nM).

Advances in the design of cost-effective, label-free, portable biosensors have led to the development of LSPRbased fiber optic sensors. Various geometric configurations have been suggested to enhance the sensitivity of the LSPR sensors. As a result, tipped, ${ }^{97}$ straight, ${ }^{88}$ tapered, ${ }^{98}$ and $\mathrm{U}$ bent $^{85}$ fiber optic probes designs have emerged. Cheng and 
Chau fabricated a colloidal gold-modified fiber optic sensor and demonstrated its applicability as an RI sensor. ${ }^{71}$ These biotin-functionalized LSPR fiber-optic probes achieved a detection limit of $98 \mathrm{pM}$ for streptavidin, which is less than that achieved by the nano-SPR chip reported by Nath and Chilkoti. ${ }^{57}$ In another approach, a tip-based miniaturized fiber optic biosensor has been demonstrated by coating the distal end of a $50-\mu \mathrm{m}$ fiber core diameter with GNP. ${ }^{97}$ Tip-based fiber optic LSPR sensor has been demonstrated for detecting biotin-avidin interactions for avidin concentrations of $20 \mu \mathrm{g} / \mathrm{mL}$. Sai et al ${ }^{85}$ reported a U shaped LSPR probe for immunosensing applications (Figure 6). These LSPR probes reached the detection limit of $0.8 \mathrm{nM}$ for anti-IgG on IgGfunctionalized surface.

Monolayers of gold colloids are generally assembled using organosilanes as linkers. Silanization of sensor substrates is a time-consuming process and may require significant pretreatment as well as post-treatment. Recently, the use of polyelectrolyte (PE) multilayers has been suggested for assembling gold nanostructures on a sensor substrate. ${ }^{88}$ PE films, eg, poly(diallyldimethyl ammoniumchloride), on gold nanostructures produce a weak negatively charged surface on which nonspecific electrostatic adsorption of streptavidin could be eliminated. ${ }^{82}$ An LSPR sensor matrix having poly(diallyldimethyl ammoniumchloride)-coated GNP has been employed for immunosensing applications using biotin-streptavidin specific interaction. The detection limit of streptavidin in a microfluidic channel was found to be $100 \mathrm{ng} / \mathrm{mL} .{ }^{82}$ In another study, GNP immobilization on fiber optic sensor probes was achieved on a PE matrix composed of

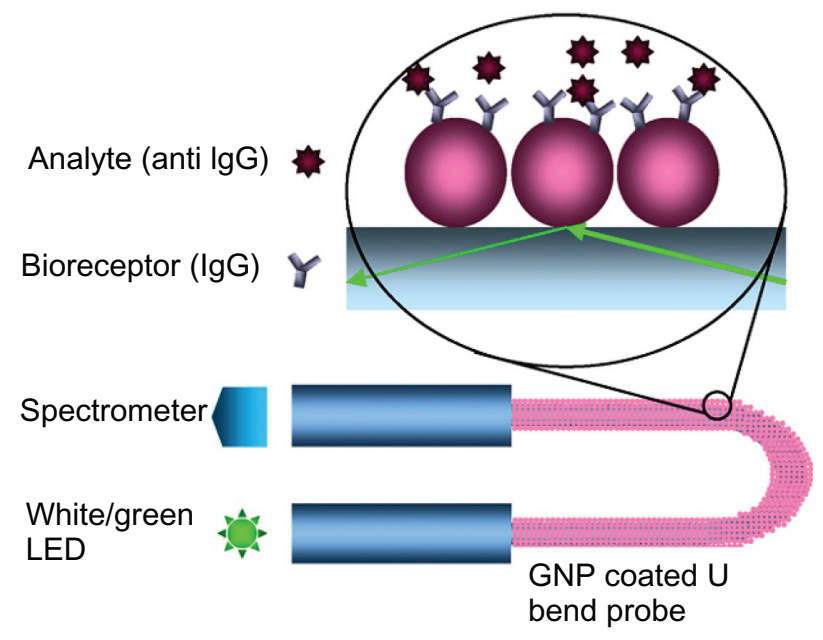

Figure 6 GNP-coated $U$ bent fiber optic probe for immunosensor application. Copyright (C) 2009, Elsevier. Reproduced with permission from Sai VVR, Kundu T, Mukherji S. Novel U-bent fiber optic probe for localized surface plasmon resonance based biosensor. Biosens Bioelectron. 2009;24:2804-2809.

Abbreviations: GNP, gold nanoparticles; LED, light-emitting diode. a trilayer of 3 different PEs [poly(diallyldimethylammonium chloride), poly(propyleneammonium chloride), and poly(styrene sulfonic acid sodium)] (Figure 7). ${ }^{88}$ This LSPR sensor matrix has shown good stability and reproducibility. Further, this fiber optic LSPR sensor showed promising potential for immunosensor applications. By modifying the sensor surface with rabbit IgG, the lowest detectable concentration was found to be $11.1 \mathrm{ng} / \mathrm{mL}$ of goat anti-rabbit $\mathrm{IgG}$.

Gold colloids have been used in conjunction with a compact microfluidic platform, enabling a fusion of plasmonics with microfluidics, for which a new term "plasmofluidics" has been coined. ${ }^{83}$ This leads to both surface plasmon-based "lab-on-a-chip" and fluid-based active plasmonics. These devices have demonstrated the capability of transporting a specific amount of biosamples into the sensing chambers to achieve sensitive and specific biosensing with decreased reaction time and less reagent consumption. Such devices, used as immunosensors, have demonstrated a detection limit of $270 \mathrm{ng} / \mathrm{mL}$ of antibiotin analyte. ${ }^{84}$

Kitano's group developed LSPR sensor chips for receptor-ligand interactions and quantification. ${ }^{72,74}$ The researchers demonstrated selective binding of concanavalin A (Con A) to the sugar residues of glycolipids immobilized on nanogold slides, with a nanomolar detection limit. ${ }^{72}$ In another study, the same group studied the sensing capability of colloidal gold monolayer modified with polymers containing phenylboronic acid terminals for detection of glycoproteins. ${ }^{74}$ These sensor chips showed a concentration-dependent binding of ovalbumin with a detection limit of $100 \mathrm{nM}$. Later, Guo et $\mathrm{al}^{75}$ suggested that incorporation of an additional monolayer (eg, alkylthiol) between the receptor (ie, glycolipid) monolayer and the transducer (ie, gold colloids) might improve the sensor performance. Integration of a 1-dodecanethiol layer between the gold colloids and the glycolipids lowered the minimum detection concentration of Con A to $0.1 \mathrm{nM}$.

\section{Nucleic acid sensor}

Miniaturized nucleic acid sensors using microarrays and biochips have received a lot of attention lately, particularly in the field of genomics and proteomics. Such devices are based on detection of supramolecular interactions, ie, hybridizations, that occur between complementary oligonucleotides, one linked to a solid surface (probe DNA) and the other one to be analyzed (target DNA). The LSPR property of gold colloids has been exploited to develop nucleic acid biosensors (Table 3).

Endo et al developed an LSPR-based DNA biosensor using a gold-capped nanoparticle layer immobilized with 


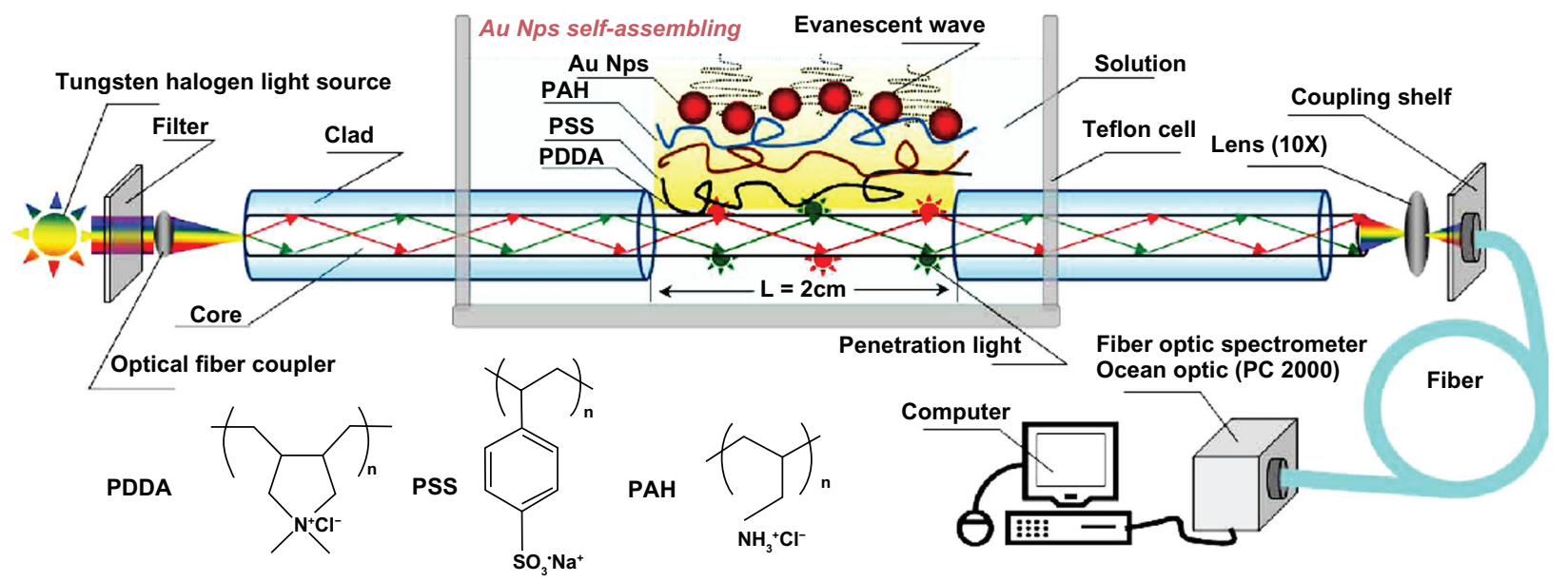

Figure 7 Trilayer of polyelectrolytes with immobilized sGNP on fiber optic probe.

Copyright @ 2010, MDPI. Reproduced with permission from Shao Y, Xu S, Zheng X, Wang Y, Xu W. Optical fiber LSPR biosensor prepared by gold nanoparticle assembly on polyelectrolyte multilayer. Sensors. 2010;10:3585-3596.

Abbreviations: PAH, poly-propyleneammonim chloride; PSS, polystyrene sulfonic acid sodium; PDDA, poly(diallyldimethylammonium chloride); Au Nps, gold nanoparticles.

peptide nucleic acids ${ }^{99}$ Hybridization interactions with target oligonucleotides could be detected down to a limit of 0.677 pM of target DNA. Selective discrimination against a single base mismatch was also achieved. In a similar fashion, a multispot gold-capped nanoparticle array (MG-NPA) chip has been fabricated recently and used for point mutation detection. ${ }^{102}$ Under optimal conditions, these MG-NPA chips achieved a picomolar limit of detection for target DNA. Also, selective discrimination against a single-base mismatch DNA sequence was achieved by using both homozygous and heterozygous DNA samples.

Cao et $\mathrm{al}^{100}$ have developed an optical nanobiosensor using $24 \mathrm{~nm}$ sGNP and successfully performed real time DNA detection. Monoclonal antibodies, c-Myc, bound nanosensor showed a linear response for PCMV-Myc plasmid detection ranging from 6.2 to $20.0 \mathrm{ng} / \mu \mathrm{L}$ concentration $\left(R^{2}=0.99\right)$. The detection limit of the DNA plasmid was $2.4 \mathrm{ng} / \mu \mathrm{L}$. The authors reported that the response concentration range and the detection limit were lower compared to the conventional methods, showing that this nanosensor could be applied to the detection of oncogenes.

\section{Toxin biosensors}

In the past few decades, a variety of pesticides has been used indiscriminately, which have posed serious environmental risks by affecting aquatic ecosystems and endangering human health as well. ${ }^{32}$ In addition to pesticides and related toxins, heavy metals and their compounds, typically discharged as industrial effluents and contaminating surface and ground water, are another category of serious environmental and clinical concern. Ingestion of such heavy metals, even in minute quantities, through food and water can cause severe health problems, including anemia, birth defects, mental retardation, and behavioral disorders. Most commonly used techniques such as liquid and gas chromatography are time consuming, and a significant amount of pretreatment of the sample is generally required. A demand to rapidly detect these organophosphorous toxins in the environment

Table 3 Nucleic acid sensors based on localized surface plasmon resonance of gold colloids

\begin{tabular}{|c|c|c|c|c|c|}
\hline Gold colloid types & Probe moieties & Analytes & Limits of detection & Device types & References \\
\hline $\begin{array}{l}\text { GNS (silica-gold; } \\
100-30 \mathrm{~nm}\end{array}$ & PNA & Target DNA & $0.677 \mathrm{pM}$ & Chip & Endo et al ${ }^{99}$ \\
\hline $\begin{array}{l}\text { Gold capped } \\
\text { oxide nanostructures } \\
(15 \mathrm{~nm})\end{array}$ & Probe DNA & Target DNA & $10 \mathrm{pM}$ & Chip & Kim et $\mathrm{al}^{94}$ \\
\hline sGNP $(24 \mathrm{~nm})$ & $\begin{array}{l}\text { c-Myc (3C7)-mouse } \\
\text { monoclonal lgG }\end{array}$ & pCMV-Myc & $2.4 \mathrm{ng} / \mathrm{mL}$ & $\begin{array}{l}\text { Gold } \\
\text { plate }\end{array}$ & Cao et al $\left.\right|^{100}$ \\
\hline $\begin{array}{l}\text { GNS (silica-gold) } \\
100-30 \mathrm{~nm}\end{array}$ & & 400-bp DNA & $4.08 \mathrm{ng} / \mathrm{mL}$ & Chip & Endo et al ${ }^{101}$ \\
\hline $\begin{array}{l}\text { GNS (silica-gold) } \\
100-30 \mathrm{~nm}\end{array}$ & Probe DNA & Target DNA & I pM & Chip & Yoo et $\mathrm{al}^{102}$ \\
\hline
\end{tabular}

Abbreviations: sGNP, spherical gold nanoparticles; PNA, peptide nucleic acid; GNS, gold nanoshells. 
as well as in human body fluids has been addressed by LSPR biosensors. Gold colloid-based LSPR sensors have also been successfully demonstrated to detect various toxic heavy metals and other toxins (Table 4 ) as a first step toward remediation of such problems.

A fiber optic biosensor for detecting paraoxon (an organophosphorous pesticide) has been developed using sGNP covalently coupled with acetylcholinesterase (AChE). ${ }^{32}$ The sensor, based on inhibition of the enzyme, showed a linear response in the range of $1-100 \mathrm{ppb}$ with $0.234 \mathrm{ppb}$ limit of detection. Also, the biosensor retained $94 \%$ of its original activity after six cycles of inhibition with $500 \mathrm{ppb}$ paraoxon followed with reactivation of $\mathrm{AChE}$ by $0.5 \mathrm{mM}$ 2-pyridine-aldoxime methoiodide. The biosensor conserved its activity and produced reproducible results after storage in a dry state at $4^{\circ} \mathrm{C}$ for 60 days. Later, the same group designed a biofunctionalized fiber optic LSPR nanobiosensor for toxic heavy metal detection, eg, lead and cadmium. ${ }^{103,104}$ The researchers found that the absorbability of the monoclonal antibody (K55061M) anchored to the LSPR sensor increased to $12.2 \%$ upon changing the $\mathrm{Pb}$ (II)-EDTA level from 10 to $100 \mathrm{ppb}$ with a detection limit of $0.27 \mathrm{ppb} .{ }^{103}$ For cadmium detection, phytochelatins (PCs) peptides were chosen as probe moiety because $\mathrm{PCs}$ are capable of forming chelates with $\mathrm{Cd}(\mathrm{II})$ by thiolate coordination. ${ }^{104}$ These PCfunctionalized fiber optic LSPR sensors showed a sensitivity of $1.24 \mathrm{ppb}^{-1}$ and a detection limit of $0.16 \mathrm{ppb}$.

An optical fiber-based LSPR sensor has been explored for the detection of staphylococcal enterotoxin B (SEB).$^{105}$ This LSPR biosensor achieved a lowest limit of detection of $\sim 1.4 \mathrm{pM}$, which compares favorably with conventional immunological methods such as western immunoblot and enzyme-linked immunosorbent assay and competing biosensor technologies such as propagating SPR sensors, bidiffractive grating sensors, and fluorescence-based sensors. Recently, the use of triangular hybrid $\mathrm{Au}-\mathrm{Ag}$ nanoparticles array was proposed for biosensing of SEB (Figure 8). ${ }^{106}$ Hybrid nanoparticles were constructed on a glass substrate employing NSL. Further, these arrays were demonstrated for SEB detection at nanogram per milliliter sensitivity using monoclonal anti-mouse SEB-anchored hybrid arrays.

\section{Miscellaneous biosensor applications}

Lee et al fabricated a tapered optical fiber-based nanoprobe for the real-time RI measurement of a single live cell by exploiting the evanescent wave-based excitation of the localized plasmons of GNP. ${ }^{98}$ By measuring the optical intensity scattered from the nanoparticles, the probe showed intensity sensitivity up to $\sim 5400 \%$ per RIU. These fiber optic nanoprobes were tested to detect the RI of 3T3 fibroblast cell by inserting the probe into the cytoplasm. The RI measured by the localized plasmonic effect was 1.3506 , which was consistent with the results of RI measurements obtained using holographic methods. Some small molecular weight molecules, eg, glucose, have been detected using LSPR of gold colloids (Table 5).

Recently, an LSPR biosensor has been fabricated on a cuttlebone-derived matrix substrate (CDMS) using sGNP and was employed for glucose detection. ${ }^{107}$ As CDMS is a three-dimensional chamber-like structure with naturally abundant amino groups, sGNP can be immobilized directly without surface modification steps. Also, the sGNP-immobilized CDMS framework resulted in effective optical signal transduction and improved the sensitivity of the detection system. The biosensor depends on the catalysis of glucose by glucose oxidase, which produces hydrogen peroxide. The peroxide produced reduces chloroauric acid. All the reactions happened in free medium and none of the ingredients were immobilized on the sGNP. The reduction of chloroauric acid caused deposition of gold on the immobilized sGNP of size 3-5 nm, thereby causing enlargement of the sGNP. This, as discussed earlier, predictably causes a shift in the LSPR peak. A reaction with glucose $\left(5 \times 10^{-5} \mathrm{M}\right)$ for 20 minutes resulted in enlargement of GNP up to $\sim 12 \mathrm{~nm}$ due to reduction of the gold salt by $\mathrm{H}_{2} \mathrm{O}_{2}$. The detection range of this biosensor was from $5 \times 10^{-6}$ to $5 \times 10^{-5} \mathrm{M}$ glucose concentrations.

Table 4 Toxin sensors based on Localized surface plasmon resonance of gold colloids

\begin{tabular}{|c|c|c|c|c|c|}
\hline Gold colloid types & Probe moieties & Analytes & Limits of detection & Device types & References \\
\hline sGNP $(9.6 \mathrm{~nm})$ & AChE & Paraoxon & $0.234 \mathrm{ppb}$ & Optical fiber & Lin et $\mathrm{al}^{32}$ \\
\hline sGNP $(9.6 \mathrm{~nm})$ & $\begin{array}{l}\text { Monoclonal antibody } \\
\text { to lead (K5506IM) }\end{array}$ & Lead & $0.27 \mathrm{ppb}$ & Optical fiber & Lin and Chung ${ }^{103}$ \\
\hline sGNP $(9.6 \mathrm{~nm})$ & Phytochelatins & Cadmium & $0.16 \mathrm{ppb}$ & Optical fiber & Lin and Chung ${ }^{104}$ \\
\hline sGNP $(9.6 \mathrm{~nm})$ & Antibody against SEB & SEB & $0.04 \mathrm{ng} / \mathrm{mL}$ & Optical fiber & Chau et al ${ }^{105}$ \\
\hline Triangular $\mathrm{Au}-\mathrm{Ag}$ & Monoclonal mouse anti- & SEB & $\mathrm{I} \mathrm{ng} / \mathrm{mL}$ & Chip & Zhu et al ${ }^{106}$ \\
\hline $\mathrm{NP}(50-5 \mathrm{~nm})$ & SEB IgG & & & & \\
\hline
\end{tabular}

Abbreviations: sGNP, spherical gold nanoparticles; SEB, staphylococcal enterotoxin B; NP, nanoparticle; AChE, acetylcholinesterase. 


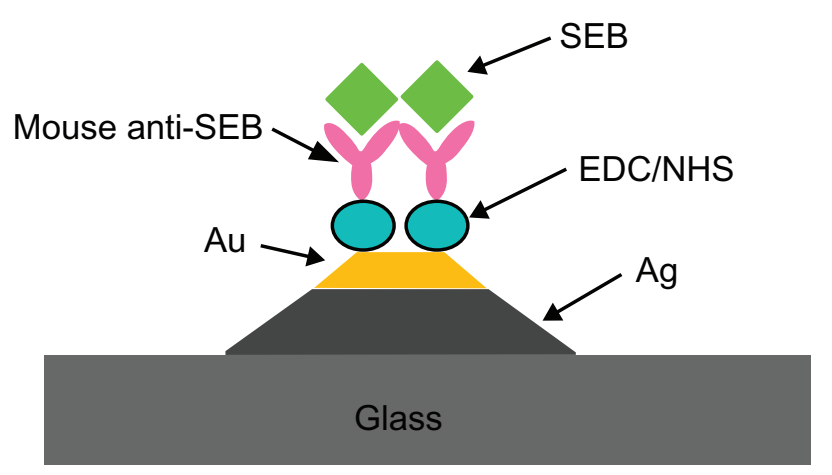

Figure 8 Schematic of localized surface plasmon resonance sensor representing the detection of SEB on mouse anti-SEB functionalized triangular Ag-Au nanoparticles. Copyright (C) 2009, Elsevier. Reproduced with permission from Zhu S, Dua C, $\mathrm{Fu}$ Y. Localized surface plasmon resonance-based hybrid Au-Ag nanoparticles for detection of Staphylococcus aureus enterotoxin B. Opt Mater. 2009;31:1608-1613. Abbreviations: SEB, staphylococcal enterotoxin B; EDC, I-ethyl-3-(3dimethylaminopropyl)carbodiimide- $\mathrm{HCl}$; NHS, N-hydroxy succinimide.

Kreuzer et al ${ }^{108}$ developed an LSPR-based rapid and cost-effective analytical method for the quantitative determination of steroid hormone (stanozolol), which is usually analyzed by chromatographic methods under standard laboratory conditions. In this assay, stanozolol-conjugated bovine serum albumin was used as a probe to specifically bind stanozolol (preincubated with stanozolol polyclonal antiserum [ $\alpha$-StpAb]). The detection limit of this system was determined to be $2.4 \mathrm{nM}(0.7 \mu \mathrm{g} / \mathrm{L})$ of stanozolol, a value below the maximum allowed level set by the International Olympic Committee for banned substances.

\section{Current trends}

In the past few years, researchers have developed green chemistry to synthesize GNP using a nontoxic and environmental friendly approach. Taking advantage of this approach, researchers have developed methods for in situ GNP synthesis and immobilization on sensor substrates. For example, Zheng et $\mathrm{al}^{109}$ reported in situ synthesis of GNP on egg shell membrane (ESM) to develop an LSPR sensor. The formation of GNP on ESM protein fibers was attributed to the reduction of $\mathrm{Au}$ (III) ions to $\mathrm{Au}(0)$ by the aldehyde moieties of the natural ESM fibers.

The inability of sGNP to quantify micron-sized analytes has restricted their use to more qualitative detection schemes. As an illustration, one might consider the example of a recent attempt to detect Salmonella via LSPR using GNP-immobilized chips fabricated through lithography. ${ }^{110}$ These chips showed a good qualitative response to the analytes, but quantification of the Salmonella cells was difficult in this sensor configuration, probably due to the fact that the maximum electromagnetic decay length (probe depth) of LSPR associated with GNP is of the order of a few nanometers. However, in the near future, the quantification of micron-sized pathogenic organisms might be possible by exploiting the capabilities of plasmonic nanorods metamaterial (probe depth $=500 \mathrm{~nm}) .{ }^{111}$

Recently developed nanosandwiches (eg, gold-silicagold, gold-cobalt-gold) $)^{112,113}$ and hybrid nanostructures (eg, $\left.\mathrm{Fe}_{3} \mathrm{O}_{4} / \mathrm{Au}\right)^{114}$ have demonstrated both plasmonic and magneto-optical properties. These combined functionalities in a single nanoarchitecture have introduced a platform for the advancement of magnetoplasmonic nanobiosensors.

\section{Conclusion}

In this review, we have highlighted several current research accomplishments in the domain of GNP-anchored LSPR biosensors. The precise control over the size, shape, and composition of GNP in nanostructure film plays a key role in engineering the LSPR properties that affect the biosensor response. Considerable effort has gone into synthesis/ fabrication techniques to construct gold nanostructures with improved uniformity, spatial distribution, and stability. Recently developed top-down approaches have provided superior control over the uniformity and reproducibility of sensor surfaces. These nanostructured films have exhibited improvement in sensor quality parameters, such as sensitivity, reusability, reproducibility, and dynamic range. The LSPR property of anchored gold nanoparticles has been coupled with a variety of sensor substrates including glass chips, optical fibers, microfluidic channels, and even biological substrates (eg, egg shell membrane, CDMS). These sensors have harnessed the optical properties of GNP and have spawned a number of useful applications for medical diagnostics and environmental monitoring. Further, these nanostructured films have been used in multiplexed mode

Table 5 Miscellaneous sensing applications based on localized surface plasmon resonance of gold colloids

\begin{tabular}{llllll}
\hline Gold colloid types & Probe moieties & Analytes & Limits of detection & Device types & References \\
\hline sGNP $(3-5 \mathrm{~nm})$ & Glucose oxidase & Glucose & $5 \mu \mathrm{M}$ & CDMS & Xu et al \\
sGNP $(100 \mathrm{~nm})$ & St-BSA & ST $(\alpha-S t \mathrm{pAb})$ & $2.4 \mathrm{nM}$ & Chip & Kreuzer et al ${ }^{108}$ \\
sGNP $(25 \mathrm{~nm})$ & Glucose oxidase & Glucose & $17 \mu \mathrm{M}$ & Egg shell membrane & Zheng et al ${ }^{109}$ \\
\hline
\end{tabular}

Abbreviations: sGNP, spherical gold nanoparticles; CDMS, cuttlebone-derived matrix substrate; St-BSA, stanozolol-conjugated bovine serum albumin. 
for simultaneous detection of multiple analytes in a given medium. These successful applications have set up a strong platform to develop versatile and portable LSPR-based biosensing devices.

Given the extensive research that has been undertaken in developing LSPR-based sensors in the past few decades, it is likely that future research in this domain will primarily concentrate on patterning nanoparticles and creation of various nanocomposites, which will allow novel sensor configurations, thereby enhancing sensitivity and/or usability. Research is underway for developing multisensor polymer chips that may be useful to detect multiple analytes at the same time by immobilizing different types of GNP on the same chip but at different sensing locations. ${ }^{115}$ Printing and deposition of nanoparticles or nanoparticle-loaded films using inexpensive printers like modified deskjet printers or soft lithography-based stamping have an important role to play in obtaining highly ordered nanostructured films. Such films may be magnetoplasmonic arrays (based on, eg, gold and iron nanoparticles), which will be used for their functional advantages. Composite nanoparticles with configurations other than core-shell structures, eg, dumbbells, may play an important role by modulating the LSPR phenomenon around the fundamental gold nanoparticle.

Overall, LSPR properties of GNP have opened up new vistas in developing sensitive and cost effective sensing devices. In the current scenario, commercialization of these laboratory-based LSPR biosensing devices is still in its infancy. Cooperation among physicists, chemists, material scientists, and biomedical engineers may be valuable in delivering these devices to the consumer's hand.

\section{Disclosure}

The authors report no conflicts of interest in this work.

\section{References}

1. Homola J. Present and future of surface plasmon resonance biosensors Anal Bioanal Chem. 2003;377:528-539.

2. Homola J. Surface plasmon resonance sensors for detection of chemical and biological species. Chem Rev. 2008;108:462-493.

3. Homola J, Yee SS, Gauglitz G. Surface plasmon resonance sensors: review. Sens Actuators B Chem. 1999;54:3-15.

4. Faraday M. Experimental relations of gold (and other metals) to light [abstract]. Philos Trans R Soc Lond. 1857;147:145-181.

5. Mie G. Beitrgeäzur Optik trüber medien, speziell kolloidaler metallösungen. Ann Phys. 1908;25:377-445.

6. Draine BT, Flatau PJ. Discrete-dipole approximation for scattering calculations. J Opt Soc Am A. 1994;11:1491-1499.

7. Futamata M, Maruyama Y, Ishikawa M. Local electric field and scattering cross section of Ag nanoparticles under surface plasmon resonance by finite difference time domain method. J Phys Chem B. 2003;107:7607-7617.
8. Willets KA, van Duyne RP. Localized surface plasmon resonance spectroscopy and sensing. Annu Rev Phys Chem. 2007;58: 267-297.

9. Underwood S, Mulvaney P. Effect of the solution refractive index on the color of gold colloids. Langmuir. 1994;10:3427-3430.

10. Haes AJ, van Duyne RP. A unified view of propagating and localized surface plasmon resonance biosensors. Anal Bioanal Chem. 2004;379:920-930.

11. Freeman RG, Grabar KC, Allison KJ, et al. Self-assembled metal colloid monolayers: an approach to SERS substrates. Science. 1995; 267:1629-1632.

12. Grubisha DS, Lipert RJ, Park HY, Driskell J, Porter MD. Femtomolar detection of prostate-specific antigen: an immunoassay based on surface-enhanced Raman scattering and immunogold labels. Anal Chem. 2003;75:5936-5943.

13. Kühn S, Håkanson U, Rogobete L, Sandoghdar V. Enhancement of single-molecule fluorescence using a gold nanoparticle as an optical nanoantenna. Phys Rev Lett. 2006;97:017402.

14. Lyon LA, Musick MD, Natan MJ. Colloidal Au-enhanced surface plasmon resonance immunosensing. Anal Chem. 1998;70: 5177-5183

15. He L, Musick MD, Nicewarner SR, et al. Colloidal Au-enhanced surface plasmon resonance for ultrasensitive detection of DNA hybridization. J Am Chem Soc. 2000;122:9071-9077.

16. Mirkin CA, Letsinger RL, Mucic RC, Storhoff JJ. A DNA-based method for rationally assembling nanoparticles into macroscopic materials. Nature. 1996;382:607-609.

17. Nam JM, Thaxton CS, Mirkin CA. Nanoparticle based bio-bar codes for the ultrasensitive detection of proteins. Science. 2003;301: 1884-1886.

18. Elghanian R, Storhoff JJ, Mucic RC, Letsinger RL, Mirkin CA. Selective colorimetric detection of polynucleotides based on the distance-dependent optical properties of gold nanoparticles. Science. 1997;277:1078-1081.

19. Daniel MC, Astruc D. Gold nanoparticles: assembly, supramolecular chemistry, quantum size related properties, and applications toward biology, catalysis, and nanotechnology. Chem Rev. 2004; 104:293-346.

20. Haes AJ, Stuart DA, Nie S, van Duyne RP. Using solution-phase nanoparticles, surface-confined nanoparticle arrays and single nanoparticles as biological sensing platforms. J Fluoresc. 2004;14: 355-367.

21. Nath N, Chilkoti A. Label free colorimetric biosensing using nanoparticles. J Fluoresc. 2004;14:377-389.

22. Roy D, Fendler J. Reflection and absorption techniques for optical characterization of chemically assembled nanomaterials. Adv Mater. 2004;16:479-508.

23. Hutter E, Fendler JH. Exploitation of localized surface plasmon resonance. Adv Mater. 2004;16:1685-1706.

24. Ghosh SK, Pal T. Interparticle coupling effect on the surface plasmon resonance of gold nanoparticles: from theory to applications. Chem Rev. 2007;107:4797-4862.

25. Pingarrón JM, Yáñez-Sedeño P, González-Cortés A. Gold nanoparticle-based electrochemical biosensors. Electrochim Acta. 2008;53:5848-5866.

26. Turkevich J, Stevenson PC, Hiller J. A study of the nucleation and growth processes in the synthesis of colloidal gold. Discuss Faraday Soc. 1951;11:55-75.

27. Grabar KC, Freeman RG, Hommer MB, Natan MJ. Preparation and characterization monolayers. Anal Chem. 1995;67:735-743.

28. Brust M, Walker M, Bethell D, Schiffrin DJ, Whyman R. Synthesis of thiol-derivatised gold nanoparticles in a two-phase liquid-liquid system. J Chem Soc Chem Commun. 1994;7:801-802.

29. Hostetler MJ, Wingate JE, Zhong CJ, et al. Alkanethiolate gold cluster molecules with core diameters from 1.5 to $5.2 \mathrm{~nm}$ : core and monolayer properties as a function of core size. Langmuir. 1998; 14:17-30. 
30. Jin Y, Kang X, Song Y, Zhang B, Cheng G, Dong S. Controlled nucleation and growth of surface-confined gold nanoparticles on a (3-aminopropyl)trimethoxysilane-modified glass slide: a strategy for SPR substrates. Anal Chem. 2001;73:2843-2849.

31. Frederix F, Friedt JM, Choi KH, et al. Biosensing based on light absorption of nanoscaled gold and silver particles. Anal Chem. 2003; 75:6894-6900.

32. Lin TJ, Huang KT, Liu CY. Determination of organophosphorous pesticides by a novel biosensor based on localized surface plasmon resonance. Biosens Bioelectron. 2006;22:513-518.

33. Aslam M, Fu L, Su M, Vijayamohanan K, Dravid VP. Novel one-step synthesis of amine-stabilized aqueous colloidal gold nanoparticles. J Mater Chem. 2004;14:1795-1797.

34. Sugunan A, Thanachayanont C, Dutta J, Hilborn JG. Heavy-metal ion sensors using chitosan-capped gold nanoparticles. Sci Technol Adv Mater. 2005;6:335-340.

35. Huang KW, Yu CJ, Tseng WL. Sensitivity enhancement in the colorimetric detection of lead(II) ion using gallic acid-capped gold nanoparticles: improving size distribution and minimizing interparticle repulsion. Biosens Bioelectron. 2010;25:984-989.

36. Anh NT, Phu DV, Duy NN, Du BD, Hien NQ. Synthesis of alginate stabilized gold nanoparticles by $\gamma$-irradiation with controllable size using different $\mathrm{Au}^{3+}$ concentration and seed particles enlargement. Radiat Phys Chem. 2010;79:405-408.

37. Jana NR, Gearheart L, Murphy CJ. Wet chemical synthesis of high aspect ratio cylindrical gold nanorods. J Phys Chem B. 2001; 105:4065-4067.

38. Nikoobakht B, El-Sayed MA. Preparation and growth mechanism of gold nanorods (NRs) using seed-mediated growth method. Chem Mater. 2003;15:1957-1962.

39. Sau TK, Murphy CJ. Room temperature, high-yield synthesis of multiple shapes of gold nanoparticles in aqueous solution. J Am Chem Soc. 2004;126:8648-8649.

40. Sun Y, Xia Y. Increased sensitivity of surface plasmon resonance of gold nanoshells compared to that of gold solid colloids in response to environmental changes. Anal Chem. 2002;74:5297-5305.

41. Liu M, Guyot-Sionnest P. Mechanism of silver(I)-assisted growth of gold nanorods and bipyramids. J Phys Chem B. 2005;109: 22192-22200.

42. Lee S, Mayer KM, Hafner JH. Improved localized surface plasmon resonance immunoassay with gold bipyramid substrates. Anal Chem. 2009;81:4450-4455.

43. Nehl CL, Liao H, Hafner JH. Optical properties of star-shaped gold nanoparticles. Nano Lett. 2006;6:683-688.

44. Sánchez-Iglesias A, Pastoriza-Santos I, Pérez-Juste J, RodríguezGonzález B, García de Abajo FJ, Liz-Marzán LM. Synthesis and optical properties of gold nanodecahedra with size control. Adv Mater. 2006;18:2529-2534.

45. Pastoriza-Santos I, Sánchez-Iglesias A, García de Abajo FJ, LizMarzán LM. Environmental optical sensitivity of gold nanodecahedra. Adv Funct Mater. 2007;17:1443-1450.

46. Werts MHV, Lambert M, Bourgoin JP, Brust M. Nanometer scale patterning of langmuir-blodgett films of gold nanoparticles by electron beam lithography. Nano Lett. 2002;2:43-47.

47. Su KH, Wei QH, Zhang X, Mock JJ, Smith DR, Schultz S. Interparticle coupling effects on plasmon resonances of nanogold particles. Nano Lett. 2003;3:1087-1090.

48. Cabrini S, Barsotti RJ, Carpentiero A, et al. Cross beam lithography (FIB+EBL) and dip pen nanolithography for nanoparticle conductivity measurements. J Vac Sci Technol B. 2005;23:2806-2810.

49. Bukasov R, Shumaker-Parry JS. Highly tunable infrared extinction properties of gold nanocrescents. Nano Lett. 2007;7: 1113-1118.

50. Malyarchuk V, Hua F, Mack NH, et al. High performance plasmonic crystal sensor formed by soft nanoimprint lithography. Opt Express. 2005;13:5669-5675.
51. Kim S, Jung JM, Choi DG, Jung HT, Yang SM. Patterned arrays of Au rings for localized surface plasmon resonance. Langmuir. 2006;22: 7109-7112.

52. Henzie J, Lee MH, Odom TW. Multiscale patterning of plasmonic metamaterials. Nat Nanotechnol. 2007;2:549-554.

53. Grabar KC, Brown KR, Keating CD, Stranick SJ, Tang SL, Natan MJ. Nanoscale characterization of gold colloid monolayers: a comparison of four techniques. Anal Chem. 1997;69:471-477.

54. Freeman RG, Grabar KC, Allison KJ, et al. Self-assembled metal colloid monolayers: an approach to SERS substrates. Science. 1995; 267:1629-1632.

55. Englebienne P. Use of colloidal gold surface plasmon resonance peak shift to infer affinity constants from the interactions between protein antigens and antibodies specific for single or multiple epitopes. Analyst. 1998;123:1599-1603.

56. Okamoto T, Yamaguchi I, Kobayashi T. Local plasmon sensor with gold colloid monolayers deposited upon glass substrates. Opt Lett. 2000;25:372-374.

57. Nath N, Chilkoti A. Label-free biosensing by surface plasmon resonance of nanoparticles on glass: optimization of nanoparticle size. Anal Chem. 2004;76:5370-5378.

58. Rance GA, Marsh DH, Khlobystov AN. Extinction coefficient analysis of small alkanethiolate-stabilised gold nanoparticles. Chem Phys Lett. 2008;460:230-236.

59. Miller M, Lazarides AA. Sensitivity of metal nanoparticle surface plasmon resonance to the dielectric environment. $J$ Phys Chem B. 2005;109:21556-21565.

60. Eustis S, El-Sayed MA. Why gold nanoparticles are more precious than pretty gold: noble metal surface plasmon resonance and its enhancement of the radiative and nonradiative properties of nanocrystals of different shapes. J Phys Chem B. 2006;110:7238-7248.

61. Jain PK, Lee KS, El-Sayed IH, El-Sayed MA. Calculated absorption and scattering properties of gold nanoparticles of different size, shape, and composition: applications in biological imaging and biomedicine. J Phys Chem B. 2006;110:7238-7248.

62. Marinakos SM, Chen S, Chilkoti A. Plasmonic detection of a model analyte in serum by a gold nanorod sensor. Anal Chem. 2007;79: $5278-5283$.

63. Chen CD, Cheng SF, Chau LK, Wang CRC. Sensing capability of the localized surface plasmon resonance of gold nanorods. Biosens Bioelectron. 2007;22:926-932.

64. Tam F, Moran C, Halas N. Geometrical parameters controlling sensitivity of nanoshell plasmon resonances to changes in dielectric environment. J Phys Chem B. 2004;108:17290-17294.

65. Yamamichi J, Iida M, Ojima T, et al. The mesoscopic effect on label-free biosensors based on localized surface plasmon resonance of immobilized colloidal gold. Sens Actuators B Chem. 2009;143: 349-356.

66. Huang H, He C, Zeng Y, et al. A novel label-free multi throughput optical biosensor based on localized surface plasmon resonance. Biosens Bioelectron. 2009;24:2255-2259.

67. Chen KJ, Lu CJ. A vapor sensor array using multiple localized surface plasmon resonance bands in a single UV-vis spectrum. Talanta. 2010; 81:1670-1675.

68. Nagatani N, Tanaka R, Yuhi T, et al. Gold nanoparticle-based novel enhancement method for the development of highly sensitive immunochromatographic test strips. Sci Technol Adv Mater. 2006;7: 270-275.

69. Zhao W, Ali MM, Aguirre SD, Brook MA, Li Y. Paper-based bioassays using gold nanoparticle colorimetric probes. Anal Chem. 2008;80: 8431-8437.

70. Nath N, Chilkoti A. A colorimetric gold nanoparticle sensor to interrogate biomolecular interactions in real time on a surface. Anal Chem. 2002;74:504-509.

71. Cheng SF, Chau LK. Colloidal gold-modified optical fiber for chemical and biochemical sensing. Anal Chem. 2003;75:16-21. 
72. Morokoshi S, Ohhori K, Mizukami K, Kitano H. Sensing capabilities of colloidal gold modified with a self-assembled monolayer of a glucose-carrying polymer chain on a glass substrate. Langmuir. 2004; 20:8897-8902.

73. Endo T, Yamamura S, Nagatani N, Morita Y, Takamura Y, Tamiya E. Localized surface plasmon resonance based optical biosensor using surface modified nanoparticle layer for label-free monitoring of antigenantibody reaction. Sci Technol Adv Mater. 2005;6: 491-500.

74. Kitano H, Anraku Y, Shinohara H. Sensing capabilities of colloidal gold monolayer modified with a phenylboronic acid-carrying polymer brush. Biomacromolecules. 2006;7:1065-1071.

75. Guo C, Boullanger P, Jiang L, Liu T. Highly sensitive gold nanoparticles biosensor chips modified with a self-assembled bilayer for detection of Con A. Biosens Bioelectron. 2007;22:1830-1834.

76. Hiep HM, Endo T, Kerman K, et al. A localized surface plasmon resonance based immunosensor for the detection of casein in milk. Sci Technol Adv Mater. 2007;8:331-338.

77. Endo T, Yamamura S, Kerman K, Tamiya E. Label-free cell-based assay using localized surface plasmon resonance biosensor. Anal Chim Acta. 2008;614:182-189.

78. Kim DK, Kerman K, Hiep HM, et al. Label-free optical detection of aptamer-protein interactions using gold-capped oxide nanostructures. Anal Biochem. 2008;379:1-7.

79. Mayer KM, Lee S, Liao H, et al. A label-free immunoassay based upon localized surface plasmon resonance of gold nanorods. ACS Nano. 2008; 2:687-692.

80. Wang Y, Qian W, Tan Y, Ding S. A label-free biosensor based on gold nanoshell monolayers for monitoring biomolecular interactions in diluted whole blood. Biosens Bioelectron. 2008;23:1166-1170.

81. Kajiura M, Nakanishi T, Iida H, Takada H, Osaka T. Biosensing by optical waveguide spectroscopy based on localized surface plasmon resonance of gold nanoparticles used as a probe or as a label. J Colloid Interface Sci. 2009;335:140-145.

82. Li X, Jiang L, Zhan Q, Qian J, He S. Localized surface plasmon resonance (LSPR) of polyelectrolyte-functionalized gold-nanoparticles for biosensing. Colloids Surf A Physicochem Eng Asp. 2009;332:172-179.

83. Huang C, Bonroy K, Reekman G, Verstreken K, Lagae L, Borghs G. An on-chip localized surface plasmon resonance-based biosensor for label-free monitoring of antigen-antibody reaction. Microelectronic Eng. 2009;86:2437-2441.

84. Huang C, Bonroy K, Reekmans G, et al. Localized surface plasmon resonance biosensor integrated with microfluidic chip. Biomed Microdevices. 2009;11:893-901.

85. Sai VVR, Kundu T, Mukherji S. Novel U-bent fiber optic probe for localized surface plasmon resonance based biosensor. Biosens Bioelectron. 2009;24:2804-2809.

86. Bi N, Sun Y, Tian Y, et al. Analysis of immunoreaction with localized surface plasmon resonance biosensor. Spectrochim Acta A Mol Biomol Spectrosc. 2010;75:1163-1167.

87. Hiep HM, Yoshikawa H, Tamiya E. Interference localized surface plasmon resonance nanosensor tailored for the detection of specific biomolecular interactions. Anal Chem. 2010;82:1221-1227.

88. Shao Y, Xu S, Zheng X, Wang Y, Xu W. Optical fiber LSPR biosensor prepared by gold nanoparticle assembly on polyelectrolyte multilayer. Sensors. 2010;10:3585-3596.

89. Nusz GJ, Curry AC, Marinakos SM, Wax A, Chilkoti A. Rational selection of gold nanorod geometry for label-free plasmonic biosensors. ACS Nano. 2009;3:795-806.

90. Nusz GJ, Marinakos SM, Curry AC, et al. Label-free plasmonic detection of biomolecular binding by a single gold nanorods. Anal Chem. 2008;80:984-989.

91. Huang H, Tang C, Zeng Y, et al. Label-free optical biosensor based on localized surface plasmon resonance of immobilized gold nanorods. Colloids Surf B Biointerfaces. 2009;71:96-101.

92. Liao H, Hafner JH. Gold nanorod bioconjugates. Chem Mater. $2005 ; 17: 4636-4641$
93. Endo T, Kerman K, Nagatani N, et al. Multiple label-free detection of antigen-antibody reaction using localized surface plasmon resonancebased core-shell structured nanoparticle layer nanochip. Anal Chem. 2006;78:6465-6475.

94. Kim DK, Kerman K, Saito M, et al. Label-free DNA biosensor based on localized surface plasmon resonance coupled with interferometry. Anal Chem. 2007;79:1855-1864.

95. Ye J, Bonroy K, Nelis D, et al. Enhanced localized surface plasmon resonance sensing on three-dimensional gold nanoparticles assemblies. Colloids Surf A Physicochem Eng Asp. 2008;321: 313-317.

96. Guo L, Chen G, Kim DH. Three-dimensionally assembled gold nanostructures for plasmonic biosensors. Anal Chem. 2010;82: 5147-5153.

97. Mitsui K, Handa Y, Kajikawa K. Optical fiber affinity biosensor based on localized surface plasmon resonance. Appl Phys Lett. 2004;85:4231-4233.

98. Lee JY, Lee CW, Lin EH, Wei PK. Single live cell refractometer using nanoparticle coated fiber tip. Appl Phys Lett. 2008;93:173110.

99. Endo T, Kerman K, Nagatani N, Takamura Y, Tamiya E. Label-free detection of peptide nucleic acid-DNA hybridization using localized surface plasmon resonance based optical biosensor. Anal Chem. 2005;77:6976-6984.

100. Cao Z, Gong FC, Tu M, et al. Preliminary recognition of c-myc gene protein using an optical biosensor with gold colloid nanoparticles based on localized surface plasmon resonance. Anal Lett. 2009; 42:2820-2837.

101. Endo T, Ikeda D, Kawakami Y, Yanagida Y, Hatsuzawa T. Fabrication of core-shell structured nanoparticle layer substrate for excitation of localized surface plasmon resonance and its optical response for DNA in aqueous conditions. Anal Chim Acta. 2010;661: 200-205.

102. Yoo SY, Kim DK, Park TJ, Kim EK, Tamiya E, Lee SY. Detection of the most common corneal dystrophies caused by BIGH3 gene point mutations using a multispot gold-capped nanoparticle array chip. Anal Chem. 2010;82:1349-1357.

103. Lin TJ, Chung MF. Using monoclonal antibody to determine lead ions with a localized surface plasmon resonance fiber-optic biosensor. Sensors. 2008;8:582-593.

104. Lin TJ, Chung MF. Detection of cadmium by a fiber-optic biosensor based on localized surface plasmon resonance. Biosens Bioelectron. 2009;24:1213-1218.

105. Chau LK, Lin YF, Cheng SF, Lin TJ. Fiber-optic chemical and biochemical probes based on localized surface plasmon resonance. Sens Actuators B Chem. 2006;113:100-105.

106. Zhu S, Dua C, Fu Y. Localized surface plasmon resonance-based hybrid $\mathrm{Au}-\mathrm{Ag}$ nanoparticles for detection of Staphylococcus aureus enterotoxin B. Opt Mater. 2009;31:1608-1613.

107. Xu G, Li H, Ma X, Jia X, Dong J, Qian W. A cuttlebone-derived matrix substrate for hydrogen peroxide/glucose detection. Biosens Bioelectron. 2009;25:362-367.

108. Kreuzer MP, Quidant R, Salvador JP, Marco MP, Badenes G. Colloidal-based localized surface plasmon resonance (LSPR) biosensor for the quantitative determination of stanozolol. Anal Bioanal Chem. 2008;391:1813-1820.

109. Zheng B, Qian L, Yuan H, et al. Preparation of gold nanoparticles on eggshell membrane and their biosensing application. Talanta. 2010; 82:177-183.

110. Fu J, Park B, Zhao Y. Limitation of a localized surface plasmon resonance sensor for Salmonella detection. Sens Actuators B Chem 2009;141:276-283.

111. Kabashin AV, Evans P, Pastkovsky S, et al. Plasmonic nanorod metamaterials for biosensing. Nat Mater. 2009;8:867-871.

112. Dmitriev A, Pakizeh T, Käll M, Sutherland DS. Gold-silica-gold nanosandwiches: tunable bimodal plasmonic resonators. Small. 2007; 3:294-299 
113. González-Díaz JB, García-Martín A, García-Martín JM, et al. Plasmonic $\mathrm{Au} / \mathrm{Co} / \mathrm{Au}$ nanosandwiches with enhanced magneto-optical activity. Small. 2008;4:202-205.

114. Wang Y, Shen Y, Xie A, Li S, Wang X, Cai Y. A simple method to construct bifunctional $\mathrm{Fe}_{3} \mathrm{O}_{4} / \mathrm{Au}$ hybrid nanostructures and tune their optical properties in the near-infrared region. J Phys Chem C. 2010; 114:4297-4301.
115. Prabhakar A, Mukherji S. Microfabricated polymer chip with integrated U-bend waveguides for evanescent field absorption based detection. Lab Chip. 2010;10:748-754.

\section{Publish your work in this journal}

Nanotechnology, Science and Applications is an international, peerreviewed, open access journal that focuses on the science of nanotechnology in a wide range of industrial and academic applications. It is characterized by the rapid reporting across all sectors, including engineering, optics, bio-medicine, cosmetics, textiles, resource sustainability and science. Applied research into nano-materials, particles, nanostructures and fabrication, diagnostics and analytics, drug delivery and toxicology constitute the primary direction of the journal. The manuscript management system is completely online and includes a very quick and fair peer-review system, which is all easy to use.

Submit your manuscript here: http://www.dovepress.com/nanotechnology-science-and-applications-journal 